\title{
Retrotransposons in the Mammalian Male Germline
}

\author{
Shumin Zhou a Akihiko Sakashita $^{\text {b Shuiqiao Yuan }}{ }^{\text {a,c }}$ Satoshi H. Namekawa ${ }^{d}$ \\ anstitute of Reproductive Health, Tongji Medical College, Huazhong University of Science and Technology, Wuhan, \\ China; ${ }^{b}$ Department of Molecular Biology, Keio University School of Medicine, Tokyo, Japan; ' Shenzhen Huazhong \\ University of Science and Technology Research Institute, Shenzhen, China; ${ }^{\mathrm{d} D e p a r t m e n t}$ of Microbiology and \\ Molecular Genetics, University of California, Davis, CA, USA
}

\section{Keywords}

DNA methylation · Histone modifications · Meiosis · piRNA · Retrotransposons · Spermatogenesis · Transposable elements

\begin{abstract}
Retrotransposons are a subset of DNA sequences that constitute a large part of the mammalian genome. They can translocate autonomously or non-autonomously, potentially jeopardizing the heritable germline genome. Retrotransposons coevolved with the host genome, and the germline is the prominent battlefield between retrotransposons and the host genome to maximize their mutual fitness. Host genomes have developed various mechanisms to suppress and control retrotransposons, including DNA methylation, histone modifications, and Piwi-interacting RNA (piRNA), for their own benefit. Thus, rapidly evolved retrotransposons often acquire positive functions, including gene regulation within the germline, conferring reproductive fitness in a species over the course of evolution. The male germline serves as an ideal model to examine the regulation and evolution of retrotransposons, resulting in genomic co-evolution with the host genome. In this review, we summarize and discuss the regulatory mechanisms of retrotransposons, stage-bystage, during male germ cell development, with a particular
\end{abstract}

Karger@karger.com

(c) 2022 S. Karger AG, Basel

www.karger.com/sxd

Karger!" focus on mice as an extensively studied mammalian model, highlighting suppression mechanisms and emerging functions of retrotransposons in the male germline.

(c) 2022 S. Karger AG, Basel

\section{Introduction}

Transposable elements (TEs) are a class of DNA sequences that can "jump" into new positions in the genomes [Rebollo et al., 2012; Bourque et al., 2018]. These insertions can generate new genes or affect the expression of neighboring genes, thereby threatening genomic integrity [Levin and Moran, 2011]. TEs comprise nearly half of the mouse and human genomes and can be subdivided into DNA transposons and retrotransposons (Fig. 1) [Lander et al., 2001; Mouse Genome Sequencing et al., 2002]. DNA transposons work by a cut-and-paste mechanism: they are cut from one genomic location and pasted into another. During the process of genomic evolution, these DNA transposons have lost their functions in the mouse and human genomes [Pace and Feschotte, 2007; Hickman and Dyda, 2016].

On the other hand, retrotransposons work by a copyand-paste mechanism, such that they are copied from one genomic location and pasted into another via reverse

Correspondence to:

Shuiqiao Yuan, shuiqiaoyuan@ hust.edu.cn

Satoshi H. Namekawa, snamekawa@ucdavis.edu 


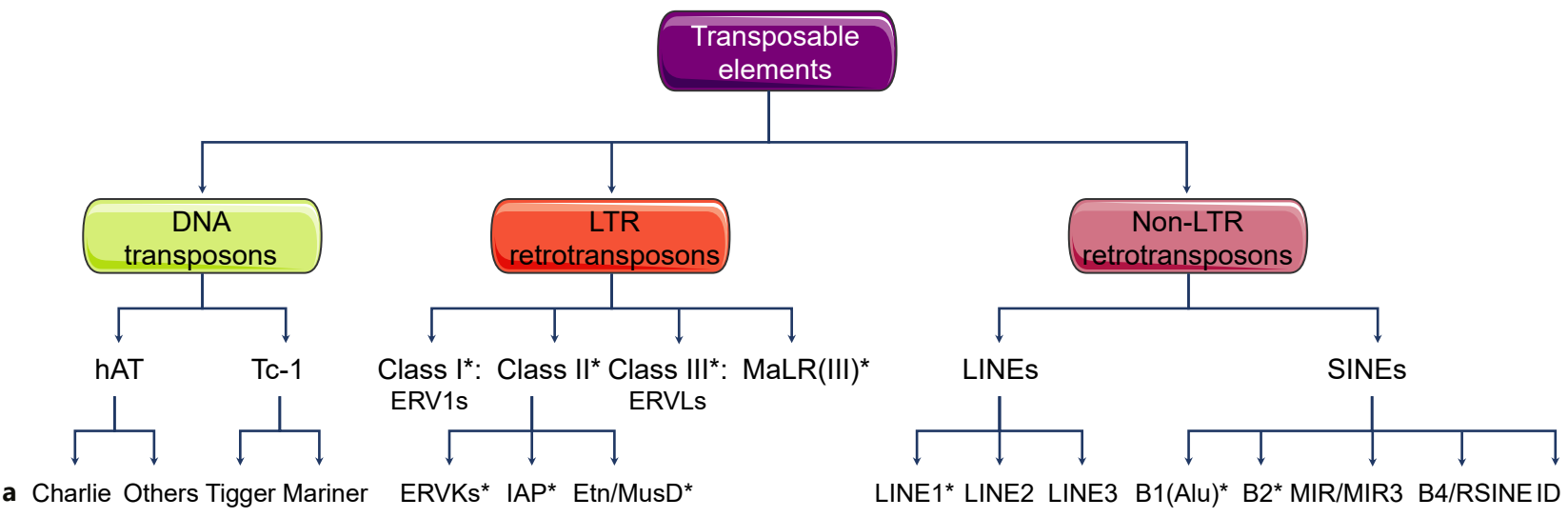

DNA transposons

'cut and paste'

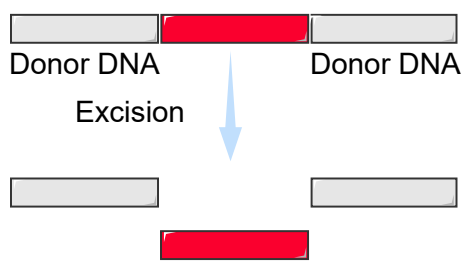

Integration

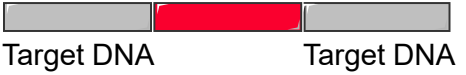

b

\section{DNA transposons}

\begin{tabular}{|l|l|l|}
\hline TIR & transposase & TIR \\
\hline
\end{tabular}

LTR retrotransposons

IAP

c

\begin{tabular}{|l|l|l|l|l|l|}
\hline 5'LTR & gag & pro & pol & 3'LTR \\
\hline
\end{tabular}

Retrotransposons

'copy and paste'

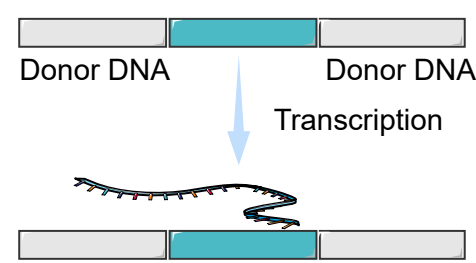

Reverse

transcription

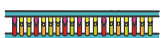

Integration

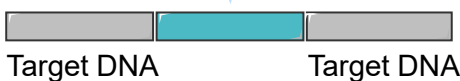

Non-LTR retrotransposons

LINE1

\begin{tabular}{|l|l|l|l|l|l|}
\hline 5'UTR & ORF2 & O'UTR \\
\hline
\end{tabular}

Non-LTR retrotransposons

SINE-Alu

\section{Left Monomer Right Monomer}


transcription using an RNA intermediate (Fig. 1b). They are subdivided into LTR (long terminal repeat) and nonLTR (non-long terminal repeat) retrotransposons (Fig. 1a). LTR retrotransposons such as endogenous retroviruses (ERVs) are relics of viral infection or retrotransposition over evolution and account for approximately 9\% of mammalian genomes [Mandal and Kazazian, 2008]. These classes of retrotransposons have lost insertional capacity in humans. Unlike human ERVs, however, some mouse ERVs are capable of active retrotransposition and serve as intracellular mutagens. Of note, most ERVs have lost their retrotransposition potential due to mutational decay, but their partial sequences, such as solo LTRs, which lost viral coding sequences, modulate host genome functions as gene regulatory elements [Thompson et al., 2016]. Non-LTR retrotransposons include LINEs (long interspersed nuclear elements) and SINEs (short interspersed nuclear elements). LINEs occupy about $20 \%$ of mammalian genomes; a subset of LINEs retain retrotransposition activities both in humans and mice. SINEs are non-autonomous transposons and use LINE1 protein for mobilization [Kramerov and Vassetzky, 2011; Raiz et al., 2012].

The germline is the most prominent battlefield between the host genome and retrotransposons, and the host genome and retrotransposons have coevolved as a result. Retrotransposons need to be expressed in the germline to propagate themselves, even as retrotransposon activity needs to be precisely controlled, since they can pose a massive threat to genome integrity. At the same time, the host genome exploits retrotransposons as functional elements to acquire reproductive fitness. During co-evolution, the mammalian host genome developed various defense mechanisms to silence and control retrotransposons for their own benefit [Zamudio and Bourc'his, 2010; Elbarbary et al., 2016]. In the male germline, there are 3 key mechanisms controlling retrotransposon activity: DNA methylation, histone modifications, and piRNA (PIWI-interacting RNAs) pathways [Bao and Yan, 2012; Di Giacomo et al., 2013; Crichton et al., 2014;

Fig. 1. Overview of transposable elements. a Categories of transposable elements. Asterisks indicate the retrotransposons that are still active in the mouse germline. $\mathbf{b}$ Self-replicated mechanisms of transposable elements. DNA transposons move around the genome by a cut-and-paste mechanism. They are excised from one genomic location and pasted into another. Retrotransposons work by a copy-and-paste mechanism, which is copied from one genomic location and pasted into another through reverse transcription using an RNA intermediate. c Schematic structure of mam-
Fu and Wang, 2014]. piRNAs are a small, noncoding RNA family with a length of $~ 24-31$ nucleotides and are critical for silencing TEs through transcriptional and post-transcriptional pathways and gene expression regulation [Iwasaki et al., 2015; Ernst et al., 2017; Czech et al., 2018; Ozata et al., 2019]. These mechanisms act in concert to regulate distinct developmental processes in the male germline.

Reasons for this stage-specific regulation may be due to the stage-specific requirement of TE functions. Recent studies have revealed various regulatory functions for TEs in the male germline. The geneticist who discovered TEs, Barbara McClintock, proposed over 70 years ago that TEs function as gene regulatory elements [McClintock, 1950]. Studies in the last decade have indeed established that TEs can impact host genomes by regulating gene expression [Rebollo et al., 2012; Friedli and Trono, 2015; Garcia-Perez et al., 2016; Thompson et al., 2016; Chuong et al., 2017]. Thus, precise, stage-specific controls of TEs are integral in the germline, and TEs often have positive functions in the germline, conferring reproductive fitness in each species over the course of evolution.

In this review, we summarize the latest research progress and discuss the regulation of retrotransposons during male germ cell development. We particularly focus on progress made in recent years following previous excellent reviews of TEs in the mammalian germline [Bao and Yan, 2012; Chuma and Nakano, 2013; Crichton et al., 2014; Fu and Wang, 2014] and highlight suppression mechanisms and emerging functions of TEs stage-bystage in the male germline.

\section{Two Major Representative Retrotransposons in the Male Germline}

\section{LTR Retrotransposons: IAP}

Mouse LTR retrotransposons that include ERVs are divided into 3 classes (Class I: ERV1s; Class II: ERVKs, IAP malian retrotransposons. IAP is characterized by long terminal repeats and gag, pro, and pol protein-coding genes. IAP belongs to ERVK/LTR families and retains insertional capacity in mice. LINE1 can encode 2 ORFs: ORF1 encodes an RNA-binding protein, and ORF2 encodes 2 enzymes - endonuclease and reverse transcriptase, which promote the LINE1 retrotransposition. TIR, two inverted tandem repeat; ORF, open reading frame; UTR, untranslated region; Gag, group-specific antigen; Pol, polymerase; LTR, long terminal repeat. 
[intracisternal A-particle], and Etn [Early Transposon]/ MusD elements; and Class III: ERVLs) (Fig. 1a); some Class II and III elements have retrotransposition functions. Several Class II elements, such as IAP and Etn/MusD elements, contribute to insertional germline mutations [Pace and Feschotte, 2007; Zhang et al., 2008; Goodier, 2016]. Further, Class III Murine ERVL (MERVL) elements, which are transcriptionally active at the time of zygotic gene activation in 2-cell stage embryos [Macfarlan et al., 2012], are potentially mutagenic. However, insertional mutations of Class III ERVL elements are much less common than those of Class II elements [Gagnier et al., 2019].

IAP is a murine-specific ERV from a large group of Class II LTR retrotransposons (also known as ERVKs) (Fig. 1a). IAP retains insertional activities in mice and is responsible for most insertional mutations in mice [Gagnier et al., 2019]. This is in stark contrast with human ERVs, which have lost retrotransposition capacity over the course of evolution. IAP has a representative retroviral structure, which contains Gag, Pro, and Pol with $5^{\prime}$ and $3^{\prime}$ long terminal repeats (LTRs) (Fig. 1c) [Mietz et al., 1987; Kuff and Lueders, 1988].

IAP shows stage-specific expression in the germline. In 1996, Dupressoir and Heidmann [1996] generated IAP LTR-driven LacZ reporter mice to test the transcriptional activities of IAP. They found that IAP's transcriptional activity is limited to prospermatogonia and undifferentiated spermatogonia. Long after this experiment, the advent of next-generation sequencing improved detection of retrotransposon activities, revealing the dynamic nature of repeat expression in spermatogenesis. A recent RNA-seq analysis revealed that the LTR of various ERVs drives noncoding RNAs in late meiotic spermatocytes [Davis et al., 2017]. Another study demonstrated that expression of TEs, including ERVs and their subtype IAPs, are dynamically altered when germ cells enter meiosis during spermatogenesis [Sakashita et al., 2020], suggesting that ERV activities are precisely controlled developmental processes in spermatogenesis.

\section{Non-LTR Retrotransposons: LINE1}

LINEs are a critical member of non-LTR retrotransposon families and make up about $17 \%$ and $19 \%$ of human and mouse genomes [Mandal and Kazazian, 2008]. LINEs are classified as LINE1, LINE2, or LINE3, with LINE1 constituting most of this group (Fig. 1a) [Mandal and Kazazian, 2008; Schumann et al., 2010]. Importantly, a subset of LINEs have retrotransposition activities; the Ta (transcribed, subset a) subfamily of L1Hs (L1 humanspecific) remains active in humans, and the L1MdA (fea- tured by A monomer), L1MdTf (featured by Tf monomer), and L1MdGf (featured by Gf monomer) copies of L1Md (Mus domesticus) families are still active in mice [Myers et al., 2002; Beck et al., 2011; Hancks and Kazazian, 2012; Sookdeo et al., 2013].

In mice, LINE1 encodes 2 open reading frames (ORFs): ORF1 and ORF2 (Fig. 1c) [Mathias et al., 1991; Martin and Bushman, 2001; Rangwala et al., 2009]. ORF1 encodes an RNA-binding protein that constitutes a complex with LINE1 RNA [Martin and Branciforte, 1993; Moran et al., 1996; Khazina and Weichenrieder, 2009; Rangwala et al., 2009]. ORF2 has 2 enzymatic activities: endonuclease and reverse transcriptase, which can excise genomic DNA and catalyze the reverse transcription of LINE1 RNA [Mathias et al., 1991; Feng et al., 1996; Moran et al., 1996]. A recent study demonstrated that LINE1 ORF1 protein starts to express from E13.5 and becomes homogenous in E15.5; importantly, LINE1 expression is associated with successful differentiation of prospermatogonia [Nguyen et al., 2020]. Consistent with this study, LINE1 ORF1 proteins were detected from E15.5 [Branciforte and Martin, 1994; Trelogan and Martin, 1995], and a portion of LINE1 loci show accessible chromatin in E17.5 [Yamanaka et al., 2019], which suggests positive functions of LINE1 in the developmental process. LINE1 expression in embryonic stages is also critical in the female germline, as LINE1 functions during perinatal oocyte attrition in normal oogenesis [Tharp et al., 2020]. In males, LINE1 expression decreases after birth and reaches a high level again in leptotene/zygotene spermatocytes [Branciforte and Martin, 1994; Trelogan and Martin, 1995]. Curiously, expression of LINE1 ORF1 takes place sporadically in a subset of spermatocytes in adult testis [Soper et al., 2008]. Further, a recent study demonstrated that LINE1 expression is dynamically changed when germ cells enter meiosis [Sakashita et al., 2020]. However, the biological significance of sporadically expressed LINE1 is enigmatic. Although LINE1 is expressed in the male germline, the retrotransposition of LINE1 predominantly exists in preimplantation embryos [Kano et al., 2009; Sookdeo et al., 2013]. Of note, LINE1 functions in gene regulation in early embryonic development [Jachowicz et al., 2017; Percharde et al., 2018].

\section{Retrotransposon Silencing in Primordial Germ Cells}

\section{Epigenetic Reprogramming}

In mice, primordial germ cells (PGCs) emerge at embryonic day (E) 7.25 and are precursors of both male and 
Fig. 2. Key mechanisms of retrotransposon silencing during mouse spermatogenesis. In PGCs, genome-wide DNA demethylation takes place, and histone modifications (H2A/H4R3me2s, H3K9me3) play an essential role in retrotransposon silencing in this stage. In prospermatogonia, de novo DNA methylation occurs, and MIWI2-directed de novo methylation is the key mechanism for transposon silencing at this stage. In spermatogonia, 3 pathways (DNA methylation, $\mathrm{H} 3 \mathrm{~K} 9 \mathrm{me} 2$, and piRNA pathway) engage in LINE1 silencing. In spermatocytes, retrotransposon silencing is post-transcriptionally regulated by pachytene piRNA. Three PIWI proteins, MIWI, MIWI2, and MILI, participate in the biogenesis of piRNAs. Among them, MIWI2 only engages in the pre-pachytene piRNA biogenesis, and MILI solely participates in the biogenesis of pachytene piRNAs. The emerging timing for each stage in mice is shown. E, embryonic days; $\mathrm{P}$, postnatal days.

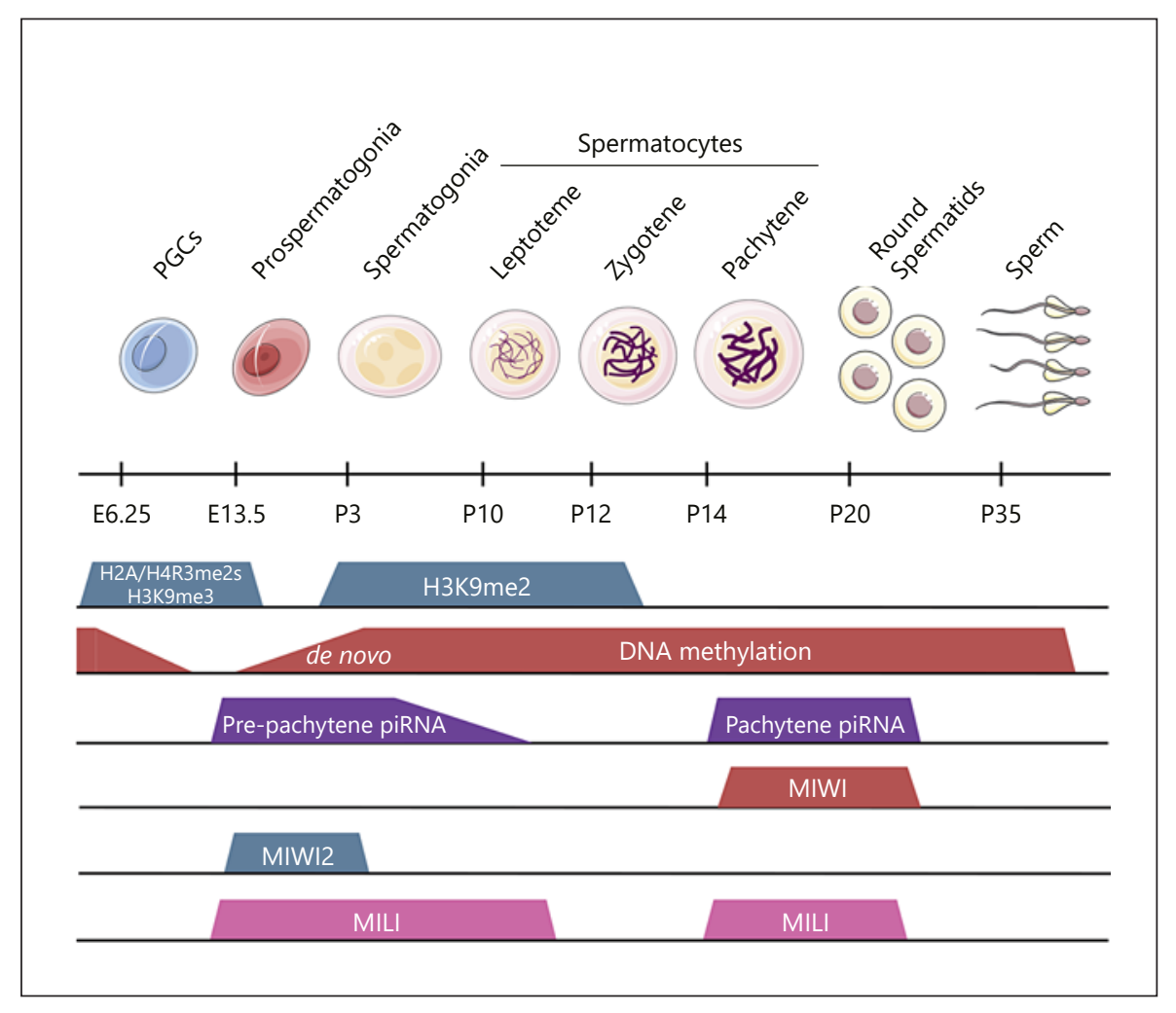

female germ cells [Lesch and Page, 2012; Saitou and Yamaji, 2012; Kelleher, 2017]. The development of PGCs consists of 3 stages: specification, migration, and differentiation [Tam and Snow, 1981; Hayashi et al., 2007]. PGCs are specified from the posterior proximal epiblast cells at E6.25 and first appear as a cluster of about 40 cells in the mesoderm at E7.25. These founder cells migrate to the developing hindgut endoderm at E7.75, then into the mesentery at E9.5, and arrive at the genital ridge at E10.5 [Seki et al., 2007; Richardson and Lehmann, 2010]. From E12.5 onwards, PGCs undergo sex-specific development and enter mitotic quiescence (male) or meiotic prophase (female) at E13.5 [Western et al., 2008; Spiller et al., 2017]. In mouse development, epigenetic reprograming takes place during PGC development to reestablish sex-specific epigenetic profiles in gametogenesis [Reik et al., 2001; Sasaki and Matsui, 2008]. This is the second wave of epigenetic reprogramming in development, the first taking place during preimplantation development to establish totipotency. Epigenetic reprogramming in PGCs includes DNA demethylation, chromatin remodeling, and erasure of genomic imprints [Hajkova, 2011], which leads to an epigenetic "ground state" of PGCs [Lesch and Page, 2012; Kobayashi et al., 2013] and initiates expression of the sexspecific genes [Jameson et al., 2012; Sakashita et al., 2015].

\section{DNA Demethylation}

Global DNA demethylation is a representative event in epigenetic reprogramming in PGCs, leading to a hypomethylation state of TEs, thereby threatening genome integrity [Lesch and Page, 2012; Smallwood and Kelsey, $2012]$. In this process, the activity of de novo DNA methyltransferases is limited due to a low expression of DNMT3A, DNMT3B, UHRF1 (DNMT1 cofactor), and DNMT3L until de novo DNA methylation takes place in later embryonic germ cells [Bourc'his et al., 2001; Seisenberger et al., 2012; Kagiwada et al., 2013]. Thus, in PGCs, maintenance of DNA methylation barely takes place, leading to replication-coupled passive DNA methylation [Kagiwada et al., 2013]. As a next step, active DNA demethylation takes place in a locus-specific manner to erase genomic imprinting and induce meiotic genes [Yamaguchi et al., 2012, 2013; Hackett et al., 2013; Vincent et al., 2013]. This delayed active demethylation is due to the DNMT1-dependent preservation of DNA methylation at imprinting control regions and meiotic genes at the first step of passive demethylation [Hargan-Calvopina et al., 2016]. Further, germline genes required for gamete generation and meiosis are activated upon DNA demethylation [Hill et al., 2018]. While a mass of retrotransposons is demethylated in PGCs, some IAP, ERV1, and ERVK 
elements are still in a high level of DNA methylation [Lane et al., 2003; Seisenberger et al., 2012; Kobayashi et al., 2013], raising the possibility that this reprogrammingresistant DNA methylation may carry heritable epigenetic information across generations [Gill et al., 2012]. However, a recent study demonstrated that variably methylated alleles of IAP loci undergo reprogramming after fertilization challenged the view that IAPs carry heritable methylation information [Kazachenka et al., 2018]. Thus, the mechanisms of heritable epigenetic states in the germline remain a looming mystery in biology.

\section{Histone Modifications}

In the male germline, DNA methylation, chromatin modifications, and the piRNA pathway are crucial for retrotransposon silencing. Global DNA methylation gradually takes place in PGCs, and piRNA does not act until E12.5; thus, additional mechanisms for retrotransposon silencing are required at this stage [Aravin et al., 2008; Kelleher, 2017]. In PGCs, histone $\mathrm{H} 2 \mathrm{~A}$ and $\mathrm{H} 4$ arginine 3 di-methylation (H2A/H4R3me2s), H3 lysine 9 trimethylation (H3K9me3), and histone $\mathrm{H} 3$ lysine 27 trimethylation (H3K27me3) are implicated in retrotransposon silencing (Fig. 2).

PRMT5, a member of the protein arginine methyltransferases (PRMTs) family that catalyzes the formation of H2A/H4R3me2s [Branscombe et al., 2001], suppresses IAP and LINE1 in PGCs to protect genomic integrity during global DNA demethylation [Kim et al., 2014]. This function of PRMT5 follows the erasure of $\mathrm{H} 3 \mathrm{~K} 9 \mathrm{me} 2$ and coincides with global epigenetic reprogramming [Kim et al., 2014]. PRMT5 also contributes to the regulation of RNA splicing to control DNA damage response in PGCs and thus maintain genomic integrity [Wang et al., 2015]. Further, FANCD2, a protein of Fanconi anemia (FA) DNA damage response pathway, works with PRMT5 to suppress IAP and LINE1 in PGCs [Nie et al., 2020]. Another critical mechanism of retrotransposons in PGCs is SETDB1, an H3K9 methyltransferase mediated H3K9me3 [Liu et al., 2014]. SETDB1-mediated H3K9me3 and H3K27me3 co-occupy the LINE1 and LTRs locus at E13.5, which suggests possible coordination between $\mathrm{H} 3 \mathrm{~K} 9 \mathrm{me} 3$ and $\mathrm{H} 3 \mathrm{~K} 27 \mathrm{me} 3$ in retrotransposon silencing. Interestingly, although $\mathrm{H} 3 \mathrm{~K} 9 \mathrm{me} 3$ and H3K27me3 are decreased at both IAP and LINE1 elements in Setdb1 mutants, expression of LINE1 was only slightly increased in mutant PGCs. Therefore, IAP and LINE1 silencing mechanisms are not identical, and additional silencing pathways may regulate LINE1 silencing [Liu et al., 2014].

\section{Retrotransposon Silencing in Prospermatogonia}

\section{De novo DNA Methylation}

Following epigenetic reprogramming of PGCs, male germ cells enter mitotic arrest and undergo de novo DNA methylation [Kota and Feil, 2010; Smallwood and Kelsey, 2012]. From E13.5 to postnatal day 3 (P3), the male germ cells in mitotic arrest are named prospermatogonia or gonocytes [Culty, 2013; McCarrey, 2013]. Two waves of de novo DNA methylation occur in prospermatogonia: the first wave of de novo DNA methylation is region-specific, and the second wave is genome-wide [Molaro et al., 2014]. By E18.5, most TEs and satellite sequences have been methylated [Kafri et al., 1992; Lees-Murdock et al., 2003; Li et al., 2004]. However, some young LINE1 and IAP retrotransposons escape this round of de novo DNA methylation and threaten genomic integrity. To neutralize this threat, PIWI (P-element-induced wimpy testis) proteins and piRNAs drive piRNA-directed de novo methylation at TE loci and post-transcriptional cleavage of TE transcripts [Aravin et al., 2008; De Fazio et al., 2011] (Fig. 2).

The DNMT3 family plays critical roles during the process of de novo methylation [Kaneda et al., 2004; Kato et al., 2007], which include DNA de novo methyltransferases DNMT3A and DNMT3B, as well as their cofactor DNMT3L [Li and Zhang, 2014]. DNMT3A is primarily responsible for de novo methylation at imprinted loci in PGCs, whereas DNMT3B is dispensable for the completion of spermatogenesis [Kaneda et al., 2004]. However, DNMT3A and DNMT3B are likely to have redundant functions; both DNMT3A and DNMT3B are involved in de novo methylation at IAP and LINE1 loci [Kato et al., 2007]. DNMT3L is an enzymatically inactive paralogue, but in the germline, the expression of DNMT3L coincides with the process of de novo methylation [Bourc'his et al., 2001]. DNMT3L engages in de novo methylation by cooperating with other DNMTs in prospermatogonia [Hata et al., 2002; Bourc'his and Bestor, 2004], and DNMT3L specifically maintains the stability of DNMT3A to facilitate DNA methylation [Veland et al., 2019]. In addition to these DNMT3 family members, a novel DNA de novo methyltransferase, DNMT3C, was recently discovered to be the repressor of evolutionarily young retrotransposons [Barau et al., 2016; Jain et al., 2017].

Of note, MORC1, a Microrchidia (Morc) family of GHKL ATPase, was found to be a critical regulator of de novo DNA methylation and suppression of specific classes of retrotransposons in PGCs [Pastor et al., 2014]. In Morc1-mutant mice, H3K4me3 is aberrantly enriched at 


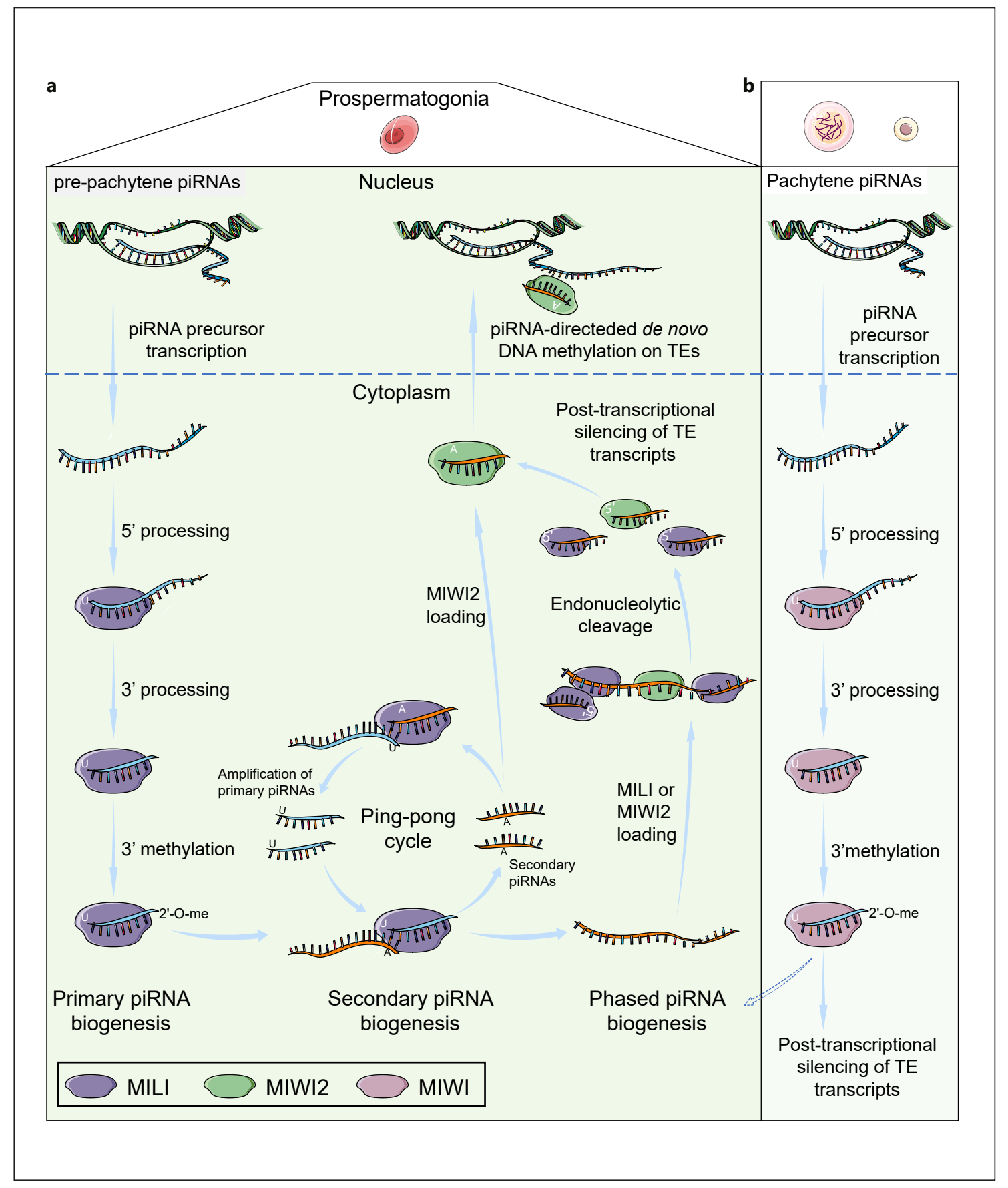

Fig. 3. PIWI-interacting RNA (piRNA) biogenesis. a Perinatal prepachytene piRNA biogenesis. Single-stranded piRNA precursors are derived from TE transcripts. Primary piRNAs are produced through the primary piRNA pathway and amplified through the ping-pong cycle. Secondary piRNAs bind to MIWI2 and are transported into the nucleus to direct de novo methylation of transposable elements. The phased piRNA production collaborates with the ping-pong pathway; the ping-pong pathway provides a responder piRNA, which initiates the production of phased piRNAs to suppress their targets at both transcriptional and posttranscriptional levels. b Pachytene piRNAs regulate TEs post-transcriptionally. Pachytene piRNA precursors are transcribed from genomic clusters lacking transposable elements and then engage in primary biogenesis as pre-pachytene piRNAs with either MILI or MIWI. Although pachytene piRNA is independent of the ping-pong cycle, phased piRNA production is a common feature both in pre-pachytene piRNA and pachytene piRNA biogenesis (shown with a dotted arrow). 
the specific regions that are failed to be de novo methylated [Pastor et al., 2014]. Since the deposition of H3K$4 \mathrm{me} 3$ counteracts the recruitment of DNMT3L and de novo DNA methylation [Ooi et al., 2007], MORC1 may facilitate the formation of unmethylated $\mathrm{H} 3 \mathrm{~K} 4$ at TE loci to establish DNMT3L-induced de novo methylation [Pastor et al., 2014].

\section{Transient Opening of Heterochromatic Domains in \\ Prospermatogonia}

In prospermatogonia, heterochromatic domains become transiently accessible, and these differentially accessible domains (DADs) occur mainly in regions with certain types of retrotransposons (such as LINE1 and ERVK) [Yamanaka et al., 2019]. Histone marks, including active marks $\mathrm{H} 3 \mathrm{~K} 4 \mathrm{me} 3$ and repressive marks $\mathrm{H} 3 \mathrm{~K}$ 9me3 and $\mathrm{H} 3 \mathrm{~K} 27 \mathrm{me} 3$, are dynamically reconstructed in the differentially accessible domains (DADs). These DADs resist the first wave of de novo DNA methylation and become open before the second wave. Concomitant with the accessible domain formations, TEs transiently generate transcripts, raising the possibility that retrotransposons in DADs may function as gene regulatory elements [Yamanaka et al., 2019].

\section{Pre-Pachytene piRNAs}

Another key event in prospermatogonia is the production of pre-pachytene piRNAs, mainly derived from TE transcripts, which are considered to be genome defense mechanisms against retrotransposons [Girard and Hannon, 2008; Senti and Brennecke, 2010]. The biogenesis of pre-pachytene piRNAs begins with the process of primary piRNA biogenesis in intermitochondrial cement (IMC, also known as Nuage or pi-body: a cellular structure found between aggregated mitochondria). Multiple mitochondrial proteins have been reported to engage in primary piRNA biogenesis [Wang et al., 2020]. Following the transcription of long single-stranded piRNA precursors, piRNA precursors might be exported into the cytoplasm with the help of Maelstrom (MAEL) [Castaneda et al., 2014]. In IMC, RNA helicase MOV10L1 and endonuclease PLD6 (MITOPLD or Zucchini) fuel piRNA precursors to produce piRNA intermediates with a $5^{\prime}$ uridine (U) end (1U bias) [Huang et al., 2011; Watanabe et al., 2011; Vourekas et al., 2015]. Then, the piRNA intermediates bind to the PIWI proteins, and their $3^{\prime}$-end are cleaved by the poly(A) specific $3^{\prime}-5^{\prime}$ exonuclease PNLDC1 acting in concert with protein TDRKH [Saxe et al., 2013; Anastasakis et al., 2016; Izumi et al., 2016; Ding et al., 2017; Zhang et al., 2017; Nishimura et al., 2018] and 2'-O- methylated by a methyltransferase HENMT1 [Saito et al., 2007; Lim et al., 2015] (Fig. 3a).

Two members of the PIWI protein family, MILI (PIWIL2) and MIWI2 (PIWIL4), are involved in pre-pachytene piRNA biogenesis (Fig. 2) [Kuramochi-Miyagawa et al., 2004; Carmell et al., 2007]. MILI is expressed from E12.5 to the adult stage, but MIWI2 is transiently expressed during E14.5-P2 (Fig. 2) [Kuramochi-Miyagawa et al., 2004; Carmell et al., 2007]. Each PIWI protein binds to specific piRNAs (about $26 \mathrm{nt}$ length for MILI, $28 \mathrm{nt}$ length for MIWI2), constituting piRNA ribonucleoprotein complexes (piRNPs) [Girard et al., 2006; Aravin et al., 2007; Iwasaki et al., 2015]. In particular, MILI is stabilized by mitochondrial outer membrane proteins, ASZ1 (GASZ) and GPAT2, in the processes of primary piRNA biogenesis and TE silencing [Ma et al., 2009; Shiromoto et al., 2013, 2019; Zhang et al., 2016].

Following the primary piRNA biogenesis, the secondary piRNA biogenesis generates and amplifies pre-pachytene piRNAs, which is called the ping-pong cycle [Ernst et al., 2017] (Fig. 3a). In this process, primary piRNAs bind to MILI, guiding the recognition of target antisense RNAs [Aravin et al., 2007; De Fazio et al., 2011]. Then, these target RNAs are cleaved between the 10th and 11th nucleotides to generate secondary piRNAs, which are characterized by an adenine (A) at the 10th nucleotide (10A bias) [Wang et al., 2009b; Ernst et al., 2017]. Subsequently, the generated secondary piRNAs bind to MILI or MIWI2 and initiate 2 distinct pathways for MILI and MIWI2 [Manakov et al., 2015]; both pathways are regulated by gametocyte-specific factor 1 (GTSF1), which forms complexes with MILI or MIWI2 [Yoshimura et al., 2009, 2018]. When secondary piRNAs bind to MILI, MILI-piRNA complexes recognize antisense RNAs and generate piRNAs with the same sequence as primary piRNAs, thereby facilitating the amplification of primary piRNAs and accomplishing a ping-pong cycle (Fig. 3) [Kuramochi-Miyagawa et al., 2008; De Fazio et al., 2011]. When secondary piRNAs bind to MIWI2, MIWI2piRNA complexes are imported into the nucleus and promote the recruitment of epigenetic silencing factors, including de novo DNA methyltransferases, contributing to the repression of young TEs [Aravin et al., 2008; Kuramochi-Miyagawa et al., 2008]. MIWI2 directly interacts with RNA transcribed from piRNA-dependent DNA methylated loci and induces piRNA-mediated DNA methylation [Watanabe et al., 2018]. Further, MIWI2-dependent piRNA biogenesis can be partly independent of MILI, revealing the distinct functions between MILI and MIWI2 [Vasiliauskaitè et al., 2017]. 
In conjunction with ping-pong amplification, another critical mechanism in piRNA production, called the phased piRNA production, generates strings of tail-tohead piRNA, one after another, from the precursor generated by the ping-pong pathway (Fig. 3a) [Han et al., 2015; Mohn et al., 2015; Ozata et al., 2019]. The linear nature of phased piRNA production enables the spreading of piRNA synthesis and increases the sequence diversity to target TEs efficiently. In phased piRNA production, MILI acts as the trigger to initiate further $5^{\prime}$ to $3^{\prime}$ processing into non-overlapping phased piRNAs, which associate with MILI in the cytoplasm and MIWI2 in the nucleus (Fig. 3a) [Yang et al., 2016]. During this process, ATPase activity of Mouse Vasa Homolog (MVH/DDX4) is required for phased piRNA production, while downstream, ATPase activity of TDRD9 is required for MIWI2-mediated transcriptional silencing of TEs in the nucleus, independent of piRNA biogenesis [Wenda et al., 2017]. Notably, the piRNA-guided PIWI-mediated production of phased piRNAs was found in a broad range of animals, revealing an evolutionarily conserved mechanism of piRNA production [Gainetdinov et al., 2018].

\section{piRNA-Directed de novo DNA Methylation}

The biogenesis of pre-pachytene piRNAs is a process of TE silencing at the post-transcriptional level [Ernst et al., 2017]. In addition, piRNA-directed de novo DNA methylation at TE loci can repress TEs at the transcriptional level [Aravin et al., 2008]; this methylation usually occurs with young TEs and TE promotor elements [Molaro et al., 2014; Manakov et al., 2015; Zoch et al., 2020]. Of all 3 PIWI proteins, MIWI2 is present in the nucleus from E14.5 to P2, and this short expression window is consistent with the window of de novo methylation [Carmell et al., 2007; Manakov et al., 2015]. During this de novo methylation process, MIWI2 can be loaded with piRNAs, forming piRNA-MIWI2 complexes, and imported into the nucleus to transcriptionally active TE loci, which will be methylated and successfully repressed [Kuramochi-Miyagawa et al., 2008; Manakov et al., 2015]; however, how piRNAs or MIWI2 direct de novo DNA methylation puzzled researchers for decades.

Recent studies addressed this question by identifying testis-specific gene 15 (TEX15) and SPOCD1 as 2 critical executors of piRNA-directed de novo methylation [Schopp et al., 2020; Yang et al., 2020; Zoch et al., 2020]. TEX15 is present in both the nucleus and cytoplasm in prospermatogonia and is highly expressed at E16.5-E18.5 and increased at P2.5 [Yang et al., 2020]. The deletion of TEX15 in mice resulted in meiotic arrest and upregula- tion of LINE1 and IAP in prospermatogonia [Yang et al., 2020]. Although TEX15 interacts with MILI, Tex15 $15^{--}$ prospermatogonia can normally generate piRNAs, form MIWI2-piRNA complexes, and transport MIWI2 into the nucleus, indicating that the piRNA pathway is intact [Yang et al., 2020]. Therefore, TEX15 likely silences retrotransposons by linking MILI to its downstream effectors. TEX15 also interacts with MIWI2 [Schopp et al., 2020; Zoch et al., 2020] and functions as a downstream effector of MIWI2-directed de novo methylation [Schopp et al., 2020]. Another protein, SPOCD1, localizes in the nucleus from E14.5 and disappears in P5, similar to the expression pattern of MIWI2 [Carmell et al., 2007; Zoch et al., 2020]. SPOCD1 is an executor of piRNA-directed de novo methylation and is required for suppression of IAP and LINE1. SPOCD1 interacts with MIWI2 and copurifies in vivo with de novo methylation apparatus (DNMT3L and DNMT3A) and repressive chromatin remodeling complexes (NURD and BAF complexes) [Zoch et al., 2020]. Thus, it was suggested that MIWI2 works with SPOCD1 to recruit de novo methylation apparatus and repressive chromatin remodeling complexes to mediate the repression of TEs. Notably, although both TEX15 and SPOCD1 are executors of piRNA-directed de novo DNA methylation, TEX15 does not interact with SPOCD1 [Schopp et al., 2020]. Thus, TEX15 and SPOCD1 may have distinct functions in piRNA-directed de novo methylation.

\section{Retrotransposon Silencing in Spermatogonia}

After birth, male germ cells re-enter the active cell cycle and migrate from the abluminal space to the basement membrane [Kluin and de Rooij, 1981; Nagano et al., 2000; Yoshida et al., 2006; Drumond et al., 2011]. During development, spermatogonia establish a heterogenous cell population comprising undifferentiated spermatogonia, including a spermatogonial stem cell population and differentiating spermatogonia. The lifelong male fertility relies on the delicate balance of self-renewal and differentiation of spermatogonial stem cells [La and Hobbs, 2019; Yoshida, 2019; Zhou et al., 2021]. Thus, the maintenance of the germline genome integrity is critical in spermatogonia, though how retrotransposons are regulated in spermatogonia that contain a stem cell population remains a mystery.

PIWI/ARGONAUTE (AGO) was initially discovered in Drosophila melanogaster as an evolutionarily conserved regulator of stem cell maintenance in diverse or- 
ganisms [Cox et al., 1998]. MILI is required for the prepachytene piRNA pathway and DNA methylation, and the global ablation of MILI in mice was initially found to result in meiotic arrest at the early pachytene stage [Kuramochi-Miyagawa et al., 2004, 2008; Aravin et al., 2008]. However, a later study demonstrated that MILI is required for spermatogonial stem cell renewal and is implicated in translation control in spermatogonia, even though retrotransposons and mRNA expression was largely unchanged in $\mathrm{Mili}^{-/-}$mice [Unhavaithaya et al., 2009]. Consistent with this observation, in the absence of both a functional piRNA pathway and DNA methylation in mitotic spermatogonia, LINE1 is still repressed; instead, a silent histone mark, $\mathrm{H} 3 \mathrm{~K} 9 \mathrm{me} 2$, was found to suppress LINE1 until spermatogonia differentiate into meiotic pachytene spermatocytes [Di Giacomo et al., 2013]. Thus, regulation of LINE1 in spermatogonia requires the cooperation of DNA methylation, the piRNA pathway, and histone modifications [Di Giacomo et al., 2013].

A mystery of the piRNA studies is that many prepachytene piRNA mutant mice manifest meiotic defects much later than the spermatogonial stage [Yang and Wang, 2016]. Further, derepression of LINE1 and IAP are prominent in pachytene spermatocytes of Dnmt3L $\mathrm{L}^{-{ }^{-}}$ and $\mathrm{Miwi}^{-/-}$mice that have defective DNA methylation in the male germline [Zamudio et al., 2015]. Therefore, retrotransposons were considered to be silent, presumably with $\mathrm{H} 3 \mathrm{~K} 9 \mathrm{me} 2$, in the absence of DNA methylation.

The function of $\mathrm{H} 3 \mathrm{~K} 9 \mathrm{me} 2$ in LINE1 suppression was later confirmed by the study showing that G9A, a H3K9 methyltransferase that mediates $\mathrm{H} 3 \mathrm{~K} 9 \mathrm{me} 2$ [Tachibana et al., 2007], is responsible for the suppression of LINE1 in mitotic spermatogonia of the Mili-null background (i.e., absence of both a functional piRNA pathway and DNA methylation) [Di Giacomo et al., 2014]. Curiously, the loss of G9A or MILI alone has no obvious impact on the expression of LINE1 in spermatogonia [Di Giacomo et al., 2014]. Therefore, G9A/H3K9me2 and MILI seem to work together to repress LINE1 in spermatogonia. The same study further highlighted a difference between the regulatory mechanisms of LINE1 and IAP; IAP was derepressed in the single Mili-null spermatogonia and was modestly derepressed in the single G9a-mutant spermatogonia [Di Giacomo et al., 2014]. This suggests that DNA methylation is the primary mechanism to repress IAP in spermatogonia.

The function of de novo DNA methylation and piRNA biogenesis in spermatogenesis were investigated in recent studies. By comparing the loss of de novo DNA methylation (loss of Dnmt3L) and the loss of piRNA biogenesis (loss of Pld6) in prospermatogonia, a recent study showed that piRNA is critical in retrotransposon silencing in prospermatogonia, but DNA methylation has more important roles in retrotransposon silencing in later stages [Inoue et al., 2017]. Importantly, the loss of de novo DNA methylation leads to ectopic activation of meiotic genes in pachytene spermatocytes [Inoue et al., 2017]. In another study, the loss of de novo DNA methylation (loss of DNMT3L or MIWI2) caused derepression of IAP and abnormal activation of neighboring transcripts, leading to rewiring of spermatogonial transcriptomes [Vasiliauskaite et al., 2018]. These altered transcriptomes are associated with defective proliferation and differentiation of spermatogonia [Vasiliauskaite et al., 2018]. Although MIWI2 is expressed in undifferentiated spermatogonia, conditional deletion of MIWI2 in spermatogonia revealed that MIWI2's function in spermatogonia is not required for later spermatogenesis [Bao et al., 2014], spermatogenic homeostasis, or regeneration [Vasiliauskaite et al., 2018], but is required for injury-induced spermatogenesis [Carrieri et al., 2017]. However, these studies used relatively young mice, and it remains an outstanding question as to how retrotransposons are controlled to sustain the long-term fertility of males.

\section{Retrotransposons in Male Meiosis}

Following spermatogonial differentiation, male germ cells enter meiosis, which is a fundamental switch in the genome to prepare the haploid genome. In meiosis, the genome undergoes meiotic recombination between homologous chromosomes that ensure the production of haploid gametes, leading to the genetic diversity of offspring [Hunter, 2015]. At the same time, germline transcriptomes, epigenomes, and 3D chromatin undergo dynamic changes in the transition from mitotic spermatogonia to meiotic spermatocytes [Hasegawa et al., 2015; Alavattam et al., 2019; Maezawa et al., 2020]. In normal germ cells, diverse and highly complex transcripts start to express in pachytene spermatocytes of meiotic prophase I [Soumillon et al., 2013]. At this transition, there are several remarkable features in the regulation of TEs. Pachytene piRNAs, a distinct class of piRNA from pre-pachytene piRNAs, start to express in the pachytene spermatocytes to suppress TEs and regulate gene expression [Ozata et al., 2019]. Somewhat counter-intuitively to the expression of pachytene piRNA, unique copies of various TEs, including SINEs, LINEs, and ERVs start to express in pachytene spermatocytes [Sakashita et al., 2020]. LTRs
10

Sex Dev

DOI: $10.1159 / 000520683$
Zhou/Sakashita/Yuan/Namekawa 
of ERVs (mainly Class III ERVLs) serve as promoters to drive the burst expression of long noncoding RNAs in pachytene spermatocytes in mice and other vertebrates [Davis et al., 2017]. Further, ERVs (mainly Class II ERVKs) can act as enhancers to drive germline genes, including species-specific genes, contributing to speciesspecific germline transcriptomes in the mouse and human germline [Sakashita et al., 2020]. These recent studies revealed positive functions of retrotransposons and the complex nature of TE regulation in male meiosis.

Importantly, meiosis is a key stage of LINE1 retrotransposition shown by a reporter transgenic mouse line in combination with a piRNA mutant line deficient for MOV10L1 [Newkirk et al., 2017]. In the absence of an intact piRNA pathway in Mov10l1 ${ }^{-1-}$ germ cells, LINE1 mRNAs were expressed prior to meiosis, but LINE1 retrotransposition was only detected in meiosis. This may be related to the unique chromatin states in meiosis. Another intriguing aspect of meiotic chromatin states is the intersection between DNA methylation and $\mathrm{H} 3 \mathrm{~K} 9 \mathrm{me} 2$, which is present until zygotene spermatocytes emerge in meiotic prophase and suppress LINE1 in normal meiosis [Di Giacomo et al., 2013]. Using 2 DNA methylation-deficient backgrounds, the Dnmt $3 L$ and Miwi2 mutant mice, H3K9me2 was shown to have been precociously lost from TEs prior to the zygotene stage. Furthermore, in these mutants, sites of TEs were ectopically selected for sites of meiotic recombination that take place in the leptotene stage [Zamudio et al., 2015]. Thereby, DNA methylation was proposed to be a mechanism to prevent the occurrence of erratic chromosomal events. Thus, in consideration of common meiotic defects of pre-pachytene piRNA mutants, it would be intriguing to speculate that pre-pachytene piRNA protects the genomic integrity of TEs from developmental events in meiosis, and the host genome efficiently removes erratic chromosomal events by strict meiotic checkpoint mechanisms [Handel and Schimenti, 2010]. In addition, H3K9me3, which is mediated by a histone methyltransferase SETDB1, is implicated in the suppression of a group of ERVs in male meiosis; Setdb1 deletion led to the mild depression of ERVs and is associated with defects in chromosome synapsis and meiotic sex chromosome inactivation [Hirota et al., 2018; Cheng et al., 2021].

Another notable feature of male meiosis is the transient reduction of DNA methylation ( $12-13$ percent reduction in the genome), which was observed at the time of premeiotic DNA replication [Gaysinskaya et al., 2018]. This is due to the hemimethylated genome after premeiotic DNA replication and the level of DNA methylation recovered at the spermatogonia level by the pachytene stage. This phenomenon appears to be related to the transient relaxation of LINE1 silencing [Soper et al., 2008; van der Heijden and Bortvin, 2009]. However, the physiological function of this transient phenomenon remains a mystery.

\section{Pachytene piRNAs and Post-transcriptional TE}

Silencing and Gene Regulation

Concurrent with monitoring of chromosome integrity by meiotic checkpoint, the completion of chromosome synapsis marks the beginning of the pachytene stage that expresses pachytene piRNAs, which suppress TEs posttranscriptionally and regulated gene expression. Due to their abundance in testes, pachytene piRNAs were the first class of piRNAs initially discovered in 2006 [Aravin et al., 2006; Girard et al., 2006; Grivna et al., 2006; Lau et al., 2006]. Distinct from pre-pachytene piRNAs, which are mainly expressed TEs, pachytene piRNAs are mostly derived from genomic clusters that are less enriched with transposable elements (the content of TEs in pachytene piRNA clusters is about 20\%; far below the genomic average) [Girard et al., 2006; Gan et al., 2011]. The expression of pachytene piRNA clusters is driven by a transcription factor A-MYB (MYBL1) [Li et al., 2013], which is a master regulator of meiotic transcripts in males [Bolcun-Filas et al., 2011]. A-MYB also drives the expression of coding genes of piRNA pathway proteins, including MIWI (PIWIL1) [Li et al., 2013]. Thus, the feed-forward mechanism underlies the robust expression of pachytene piRNAs. Further, A-MYB is required for the global establishment of meiotic enhancers, including super-enhancers and ERV-driven enhancers [Maezawa et al., 2020; Sakashita et al., 2020]. Together, pachytene piRNA production is linked to the establishment of meiotic transcriptomes.

MIWI and MILI are 2 mouse PIWI proteins that participate in the biogenesis of pachytene piRNA. MIWI is expressed specifically in mid-pachytene spermatocytes, reaching a high level in diplotene spermatocytes and becoming undetectable in step 3 round spermatids (Fig. 2) [Deng and Lin, 2002]. The global knockout of MIWI in mice causes spermatogenic arrest in step 4 round spermatids [Deng and Lin, 2002] and the upregulation of LINE1 in both spermatocytes and round spermatids [Reuter et al., 2011]. A point mutation in MIWI's slicer domain resulted in the upregulation of LINE1 without affecting MIWI protein abundance and primary piRNA biogenesis, indicating that the silencing of LINE1 relies on the slicer activity of MIWI [Reuter et 
al., 2011]. On the other hand, MILI engages both in prepachytene piRNA biogenesis and pachytene piRNA biogenesis, and MILI's slicer activity is essential for silencing of LINE1 in spermatocytes [De Fazio et al., 2011]. In contrast with the $\mathrm{Miwi}^{-1-}$ spermatids, neither LINE1 nor IAP is upregulated in $\mathrm{Mili}^{-/-}$spermatids, indicating that MIWI, but not MILI, is critical for retrotransposon silencing in spermatids [Di Giacomo et al., 2013].

While the ping-pong cycle is associated with the biogenesis of pre-pachytene piRNAs [Aravin et al., 2008], the biogenesis of pachytene piRNAs is not associated with the ping-pong cycle [Beyret et al., 2012; Iwasaki et al., 2015] (Fig. 3b). In spermatocytes, a Tudor protein RNF17 suppresses the ping-pong cycle; interestingly, the loss of RNF17 restarts the ping-pong cycle and generates more piRNAs that can be mapped to young transposons such as LINE1 [Wasik et al., 2015]. These LINE1 piRNAs contain adenine (A) at position 10 from $5^{\prime}$ UTR, which is a characteristic of secondary piRNAs generated by the ping-pong cycle.

Although pachytene piRNA is independent of the ping-pong cycle, it is associated with phased piRNA production. The poly(A) specific $3^{\prime}-5^{\prime}$ exonuclease PNLDC1 is required for precursor piRNA trimming in pachytene piRNA biogenesis and LINE1 silencing [Ding et al., 2017; Nishimura et al., 2018]. PNLDC1-dependent trimming is required for tail-to-head strings of phased precursor piRNAs and phased piRNA production in pachytene piRNA [Ding et al., 2017; Gainetdinov et al., 2018]. Thus, phased piRNA production is a common feature both in prepachytene piRNA and pachytene piRNA biogenesis (Fig. 3b).

In addition, UHRF1, a multi-functional epigenetic regulator and DNMT1 cofactor, interacts with PIWI proteins (such as MIWI, MILI) and regulates distinct aspects of DNA methylation and piRNAs [Dong et al., 2019]. The loss of Uhrf1 in differentiating spermatogonia (Stra8-Cre mediated) led to a reduction or mislocalization of PIWI proteins and derepression of some of the retrotransposons, suggesting UHRF1 may be involved in the piRNA pathway for regulating retrotransposons in the male germline. Strikingly, the pachytene piRNA populations were found to be decreased in Uhrf1 knockout testes [Dong et al., 2019]. UHRF1 changes its subnuclear localization from the nucleus to the cytoplasm in the leptotene to pachytene stages, and UHRF1 interacts with PRMT5 and colocalizes together in the nucleus of pachytene spermatocytes [Dong et al., 2019]. PRMT5 is essential in spermatogenesis and is translocated from the cytoplasm to the nucleolus prior to the pachytene stage [Wang et al., 2015]. Thus, UHRF1 likely works together with PRMT5 and potentially links transcriptional regulation in the nucleus and post-transcriptional regulation in the cytoplasm.

The mystery of pachytene piRNA is the negative representation of retrotransposons in the pachytene piRNA clusters. Studies in the past decade revealed that pachytene piRNA is critical for post-transcriptional gene regulation in late spermatogenesis. piRNA pathways regulate the degradation of mRNAs and lncRNAs post-transcriptionally through retrotransposon sequences within the piRNAs [Watanabe et al., 2015]. Further, MIWI and pachytene piRNA mediate cleavage of messenger RNA [Goh et al., 2015; Zhang et al., 2015]. Thus, mounting evidence established that pachytene piRNA regulates gene expression that is required for spermiogenesis.

\section{Retrotransposon Silencing and piRNA Functions in Spermatids}

After meiosis, 1 spermatocyte can develop into 4 round spermatids, which undergo nuclear elongation and chromatin reorganization before developing into spermatozoa [Rathke et al., 2014]. Of 3 PIWI proteins, MILI and MIWI are expressed in early round spermatids (Fig. 2). However, the loss of MIWI but not MILI leads to the upregulation of LINE1 in spermatids, indicating that MIWI is essential for the silence of LINE1 in spermatids, though MILI has less of an impact on LINE1 silencing [Deng and Lin, 2002; Di Giacomo et al., 2013]. The underlying molecular mechanism of retrotransposon silencing in spermatids remains unclear.

piRNA is critical in post-transcriptional gene regulation and translation in haploid spermatids. Mael-null mutant testes with the 129 background possess low levels of piRNAs derived from MAEL-associated piRNA precursors and exhibit reduced translation of numerous spermatogenic mRNAs, including those encoding acrosome and flagellum proteins [Castaneda et al., 2014]. A later study demonstrated the mechanisms underlying this process: function of MIWI/piRNA in the translation control of a subset of mRNA in mouse spermatids [Dai et al., 2019]. Pachytene piRNA instructs massive mRNA elimination in elongating spermatids to prepare sperm [Gou et al., 2014]. Further, genes essential for sperm functions are regulated by one of the pachytene piRNA clusters, pi6 piRNAs [Wu et al., 2020].
12

Sex Dev

DOI: $10.1159 / 000520683$
Zhou/Sakashita/Yuan/Namekawa 
Table 1. Recently discovered and representative factors against retrotransposons in the male germline

\begin{tabular}{|c|c|c|c|}
\hline Name & Function & Biological phenotype & Reference \\
\hline SETDB1 & H3K9 methylation & Depletion of PGCs & [Liu et al., 2014] \\
\hline PRMT5 & Arginine methylation of $\mathrm{H} 2 \mathrm{~A} / \mathrm{H} 4 \mathrm{R} 3 \mathrm{me} 2 \mathrm{~s}$ & Depletion of PGCs & [Kim et al., 2014] \\
\hline FANCD2 & Arginine methylation of $\mathrm{H} 2 \mathrm{~A} / \mathrm{H} 4 \mathrm{R} 3 \mathrm{me} 2 \mathrm{~s}$ & Depletion of PGCs & [Nie et al., 2020] \\
\hline G9A & H3K9 methylation & Depletion of spermatogonia & [Di Giacomo et al., 2014] \\
\hline DNMT3L & De novo DNA methyltransferase cofactor & Meiotic arrest & $\begin{array}{l}\text { [Bourc'his and Bestor, 2004; Webster et al., } \\
\text { 2005; Kato et al., 2007] }\end{array}$ \\
\hline SPOCD1 & piRNA-directed de novo DNA methylation & Meiotic arrest & [Zoch et al., 2020] \\
\hline TEX15 & piRNA-directed de novo DNA methylation & Meiotic arrest & [Schopp et al., 2020; Yang et al., 2020] \\
\hline MIWI2 & piRNA biogenesis and piRNA directed de novo methylation & Meiotic arrest & [Carmell et al., 2007; Manakov et al., 2015] \\
\hline MILI & piRNA biogenesis & Meiotic arrest & [Aravin et al., 2007; De Fazio et al., 2011] \\
\hline GPAT2 & piRNA biogenesis & Meiotic arrest & [Shiromoto et al., 2013, 2019] \\
\hline UHRF1 & piRNA biogenesis, DNA methylation and histone modifications & Meiotic arrest & [Dong et al., 2019] \\
\hline MIWI & piRNA biogenesis & Spermiogenic arrest & [Reuter et al., 2011] \\
\hline PNLDC1 & piRNA biogenesis & Spermiogenic arrest & [Ding et al., 2017; Zhang et al., 2017] \\
\hline
\end{tabular}

\section{Evolutionary Aspects of Retrotransposons in the Germline}

piRNA is considered to be an innate defense mechanism to cope with endogenous retrovirus integration. Using a Koala model, unspliced provirus transcripts were shown to be processed to piRNA to suppress integration of active retrovirus [Yu et al., 2019]. Thus, in the germline, it is likely that piRNA immediately operates to safeguard the integrity of the genome from retrotransposon invasion before adaptive immunity develops [Haase and Macfarlan, 2019]. Over the course of evolution, the host genome also utilized retrotransposons, which acquire beneficial transcription factor binding sites and the integration of which confers reproductive fitness to drive species-specific germline transcriptomes [Sakashita et al., 2020]. Further, pachytene piRNA clusters are rapidly evolved and divergent, as shown in humans [Ozata et al., 2020]; thus, acquiring new pachytene piRNA clusters confers reproductive fitness in terms of gene regulation. Further, there could be another layer of mechanisms to safeguard the integrity of the genome. Together, it is conceivable that pachytene piRNAs and retrotransposon expressions are meiotic landmarks in the battle between retrotransposons and the host genome, wherein the host genome likely exploits retrotransposons and pachytene piRNA for the sake of reproduction and evolution. An immediate response to retrovirus integration by piRNA could be followed by a latent response, which involves the Krüppel-associated box (KRAB)-Zinc Finger proteins (ZFPs). This family of proteins has coevolved with ERVs to suppress ERV expression as a consequence of an evo-

Retrotransposons in the Male Germline lutionary arms race between ERVs and the host genome [Ecco et al., 2016; Imbeault et al., 2017; Bruno et al., 2019; Senft and Macfarlan, 2021]. Thus, the multi-layered mechanisms may operate to precisely control the activities of retrotransposons in the germline.

\section{Conclusion}

The germline is a unique place where retrotransposons need to be activated for self-propagation. Retrotransposons are dynamically regulated in each stage of the male germline. In PGCs, histone modification-based mechanisms account for TE silencing when the genome undergoes epigenetic reprogramming and DNA demethylation. In prospermatogonia, pre-pachytene piRNAs suppress their targets at both transcriptional and posttranscriptional levels. In spermatogonia, LINE1 silencing is mediated by a combination of DNA methylation, histone modifications, and piRNA pathways. Meiosis is the unique stage where retrotransposon activity changes, LINE retrotranspositions occur, and pachytene piRNAs start to suppress TEs and regulate gene expression.

The piRNA pathway is the key mechanism to silence retrotransposons in the germline, and various key regulators have been recently identified. Loss of piRNA pathway components resulted in spermatogenic defects, mainly at 2 stages: meiosis and spermiogenesis. The lossof-functions of genes required for pre-pachytene piRNA biogenesis (Mili, Miwi2, Tdrkh, Tdrd1, Tdrd9, Ddx4, Movl10l1, Mael, Asz1, and Pld6) and those required for 
MIWI2-directed de novo methylation (Spocd1 and Tex15) lead to meiotic arrest and upregulation of retrotransposons (Table 1) [Aravin et al., 2007; Soper et al., 2008; Ma et al., 2009; Shoji et al., 2009; Wang et al., 2009a; Kuramochi-Miyagawa et al., 2010; Zheng et al., 2010; Watanabe et al., 2011; Saxe et al., 2013; Schopp et al., 2020; Zoch et al., 2020]. In addition to retrotransposon silencing, pachytene piRNA has profound functions in gene regulation in spermiogenesis. The loss of Mili, Miwi, Mov10l1, Tdrd1, Tdrd5, or Pnldc1 in spermatocytes leads to spermiogenic arrest; however, retrotransposon silencing likely relies on the slicer activity of PIWI proteins rather than the biogenesis of pachytene piRNAs [Deng and Lin, 2002; Wang et al., 2009a; Zheng et al., 2010; Yabuta et al., 2011; Ding et al., 2017].

Precise controls of TEs are integral in the germline, and TEs often have positive functions in the germline, conferring reproductive fitness in each species over the course of evolution. This review summarizes stage-bystage regulatory mechanisms for TEs in the germline and emerging positive functions of TEs as gene regulatory elements. The distinct regulation of TEs in each stage of the germline suggests that TEs must be activated at least once in the germline for their propagation, a requirement that has been exploited by their hosts. Such evolutionary traits are particularly evident in the regulation of piRNA and retrotransposons in meiosis and subsequent postmeiotic stages. Our review highlights the tip of the iceberg regarding the regulatory mechanisms and functions of TEs as key determinants of developmental and evolutionary processes of the germline. We anticipate that these concepts can be substantiated in future studies. Although we focused on representative types of retrotransposons in this review article, thousands of unique copies exist in the genome. In this era of genomics and systems biology, we have the opportunity to achieve a much greater understanding of the precise regulation, functions, and evolutionary aspects of retrotransposons in the germline.

\section{Acknowledgment}

We thank Yasuhisa Munakata and Kai Otsuka for critical reading of the manuscript, the members of the Yuan and the Namekawa laboratories for the discussion of this work, and Katie Gerhardt for editing the manuscript.

\section{Conflict of Interest Statement}

The authors have no conflicts of interest to declare.

\section{Funding Sources}

This study was supported by the National Natural Science Foundation of China (81971444 to S.Y), the Science Technology and Innovation Commission of Shenzhen Municipality (JCYJ20170818160910316 to S.Y.), and National Institute of Health grants (R01GM098605, R01GM122776, R35GM141085 to S.H.N.).

\section{Author Contributions}

S.Y. and S.H.N. conceived the concept of the manuscript. S.Z., A.S., S.Y., and S.H.N. reviewed the literature and wrote the manuscript.

\section{References}

Alavattam KG, Maezawa S, Sakashita A, Khoury H, Barski A, Kaplan N, et al. Attenuated chromatin compartmentalization in meiosis and its maturation in sperm development. Nat Struct Mol Biol. 2019;26:175-84.

Anastasakis D, Skeparnias I, Shaukat AN, Grafanaki K, Kanellou A, Taraviras S, et al. Mammalian PNLDC1 is a novel poly(A) specific exonuclease with discrete expression during early development. Nucleic Acids Res. 2016; 44:8908-20.

Aravin A, Gaidatzis D, Pfeffer S, Lagos-Quintana $\mathrm{M}$, Landgraf $\mathrm{P}$, Iovino N, et al. A novel class of small RNAs bind to MILI protein in mouse testes. Nature. 2006;442:203-7.

Aravin AA, Sachidanandam R, Girard A, FejesToth K, Hannon GJ. Developmentally regulated piRNA clusters implicate MILI in transposon control. Science. 2007;316:744-7.
Aravin AA, Sachidanandam R, Bourc'his D, Schaefer C, Pezic D, Toth KF, et al. A piRNA pathway primed by individual transposons is linked to de novo DNA methylation in mice. Mol Cell. 2008;31:785-99.

Bao J, Yan W. Male germline control of transposable elements. Biol Reprod. 2012;86(162): 162-14.

Bao J, Zhang Y, Schuster AS, Ortogero N, Nilsson EE, Skinner MK, et al. Conditional inactivation of Miwi2 reveals that MIWI2 is only essential for prospermatogonial development in mice. Cell Death Differ. 2014;21: 783-96.

Barau J, Teissandier A, Zamudio N, Roy S, Nalesso V, Herault Y, et al. The DNA methyltransferase DNMT3C protects male germ cells from transposon activity. Science. 2016; 354:909-12.
Beck CR, Garcia-Perez JL, Badge RM, Moran JV. LINE-1 elements in structural variation and disease. Annu Rev Genomics Hum Genet. 2011;12:187-215.

Beyret E, Liu N, Lin H. piRNA biogenesis during adult spermatogenesis in mice is independent of the ping-pong mechanism. Cell Res. 2012; 22:1429-39.

Bolcun-Filas E, Bannister LA, Barash A, Schimenti KJ, Hartford SA, Eppig JJ, et al. A-MYB (MYBL1) transcription factor is a master regulator of male meiosis. Development. 2011;138:3319-30.

Bourc'his D, Bestor TH. Meiotic catastrophe and retrotransposon reactivation in male germ cells lacking Dnmt3L. Nature. 2004;431:96-9.

Bourc'his D, Xu GL, Lin CS, Bollman B, Bestor TH. Dnmt3L and the establishment of maternal genomic imprints. Science. 2001;294 2536-9. 
Bourque G, Burns KH, Gehring M, Gorbunova V, Seluanov A, Hammell M, et al. Ten things you should know about transposable elements. Genome Biol. 2018;19:199.

Branciforte D, Martin SL. Developmental and cell type specificity of LINE-1 expression in mouse testis: implications for transposition. Mol Cell Biol. 1994;14:2584-92.

Branscombe TL, Frankel A, Lee JH, Cook JR, Yang Z, Pestka S, et al. PRMT5 (Janus kinasebinding protein 1) catalyzes the formation of symmetric dimethylarginine residues in proteins. J Biol Chem. 2001;276:32971-6.

Bruno M, Mahgoub M, Macfarlan TS. The Arms Race Between KRAB-Zinc Finger Proteins and Endogenous Retroelements and Its Impact on Mammals. Annu Rev Genet. 2019;53: 393-416.

Carmell MA, Girard A, van de Kant HJ, Bourc'his D, Bestor TH, de Rooij DG, et al. MIWI2 is essential for spermatogenesis and repression of transposons in the mouse male germline. Dev Cell. 2007;12:503-14.

Carrieri C, Comazzetto S, Grover A, Morgan M, Buness A, Nerlov C, et al. A transit-amplifying population underpins the efficient regenerative capacity of the testis. J Exp Med. 2017; 214:1631-41.

Castaneda J, Genzor P, van der Heijden GW, Sarkeshik A, Yates JR 3rd, Ingolia NT, et al. Reduced pachytene piRNAs and translation underlie spermiogenic arrest in Maelstrom mutant mice. EMBO J. 2014;33:1999-2019.

Cheng EC, Hsieh CL, Liu N, Wang J, Zhong M, Chen T, et al. The Essential Function of SETDB1 in Homologous Chromosome Pairing and Synapsis during Meiosis. Cell Rep. 2021; 34(1): 108575

Chuma S, Nakano T. piRNA and spermatogenesis in mice. Philos Trans R Soc Lond B Biol Sci. 2013;368:20110338.

Chuong EB, Elde NC, Feschotte C. Regulatory activities of transposable elements: from conflicts to benefits. Nat Rev Genet. 2017;18:7186.

Cox DN, Chao A, Baker J, Chang L, Qiao D, Lin $\mathrm{H}$. A novel class of evolutionarily conserved genes defined by piwi are essential for stem cell self-renewal. Genes Dev. 1998;12:371527.

Crichton JH, Dunican DS, Maclennan M, Meehan RR, Adams IR. Defending the genome from the enemy within: mechanisms of retrotransposon suppression in the mouse germline. Cell Mol Life Sci. 2014;71:1581605.

Culty M. Gonocytes, from the fifties to the present: is there a reason to change the name? Biol Reprod. 2013;89:46.

Czech B, Munafò M, Ciabrelli F, Eastwood EL, Fabry MH, Kneuss E, et al. piRNA-Guided Genome Defense: From Biogenesis to Silencing. Annu Rev Genet. 2018;52:131-57.

Dai P, Wang X, Gou LT, Li ZT, Wen Z, Chen ZG, et al. A Translation-Activating Function of MIWI/piRNA during Mouse Spermiogenesis. Cell. 2019;179:1566e1516-e16.
Davis MP, Carrieri C, Saini HK, van Dongen S, Leonardi T, Bussotti G, et al. Transposondriven transcription is a conserved feature of vertebrate spermatogenesis and transcript evolution. EMBO Rep. 2017;18:1231-47.

De Fazio S, Bartonicek N, Di Giacomo M, AbreuGoodger C, Sankar A, Funaya C, et al. The endonuclease activity of Mili fuels piRNA amplification that silences LINE1 elements. Nature. 2011;480:259-63.

Deng W, Lin H. miwi, a murine homolog of piwi, encodes a cytoplasmic protein essential for spermatogenesis. Dev Cell. 2002;2:819-30.

Di Giacomo M, Comazzetto S, Saini H, De Fazio S, Carrieri C, Morgan M, et al. Multiple epigenetic mechanisms and the piRNA pathway enforce LINE1 silencing during adult spermatogenesis. Mol Cell. 2013;50:601-8.

Di Giacomo M, Comazzetto S, Sampath SC, Sampath SC, O'Carroll D. G9a co-suppresses LINE1 elements in spermatogonia. Epigenetics Chromatin. 2014;7:24.

Ding D, Liu J, Dong K, Midic U, Hess RA, Xie H, et al. PNLDC1 is essential for piRNA 3' end trimming and transposon silencing during spermatogenesis in mice. Nat Commun. 2017;8:819.

Dong J, Wang X, Cao C, Wen Y, Sakashita A, Chen S, et al. UHRF1 suppresses retrotransposons and cooperates with PRMT5 and PIWI proteins in male germ cells. Nat Commun. 2019;10:4705.

Drumond AL, Meistrich ML, Chiarini-Garcia H. Spermatogonial morphology and kinetics during testis development in mice: a high-resolution light microscopy approach. Reproduction. 2011;142:145-55.

Dupressoir A, Heidmann T. Germ line-specific expression of intracisternal A-particle retrotransposons in transgenic mice. Mol Cell Biol. 1996;16:4495-503.

Ecco G, Cassano M, Kauzlaric A, Duc J, Coluccio A, Offner S, et al. Transposable Elements and Their KRAB-ZFP Controllers Regulate Gene Expression in Adult Tissues. Dev Cell. 2016; 36:611-23.

Elbarbary RA, Lucas BA, Maquat LE. Retrotransposons as regulators of gene expression. Science. 2016;351: $\mathrm{aac} 7247$.

Ernst C, Odom DT, Kutter C. The emergence of piRNAs against transposon invasion to preserve mammalian genome integrity. Nat Commun. 2017;8:1411.

Feng Q, Moran JV, Kazazian HH Jr., Boeke JD. Human L1 retrotransposon encodes a conserved endonuclease required for retrotransposition. Cell. 1996;87:905-16.

Friedli M, Trono D. The developmental control of transposable elements and the evolution of higher species. Annu Rev Cell Dev Biol. 2015; 31:429-51.

Fu Q, Wang PJ. Mammalian piRNAs: Biogenesis, function, and mysteries. Spermatogenesis. 2014;4:e27889.

Gagnier L, Belancio VP, Mager DL. Mouse germ line mutations due to retrotransposon insertions. Mob DNA. 2019;10:15.
Gainetdinov I, Colpan C, Arif A, Cecchini K, Zamore PD. A Single Mechanism of Biogenesis, Initiated and Directed by PIWI Proteins, Explains piRNA Production in Most Animals. Mol Cell. 2018;71:775e775e5.

Gan H, Lin X, Zhang Z, Zhang W, Liao S, Wang $\mathrm{L}$, et al. piRNA profiling during specific stages of mouse spermatogenesis. RNA. 2011;17: 1191-203.

Garcia-Perez JL, Widmann TJ, Adams IR. The impact of transposable elements on mammalian development. Development. 2016;143: 4101-14.

Gaysinskaya V, Miller BF, De Luca C, van der Heijden GW, Hansen KD, Bortvin A. Transient reduction of DNA methylation at the onset of meiosis in male mice. Epigenetics Chromatin. 2018;11:15.

Gill ME, Erkek S, Peters AH. Parental epigenetic control of embryogenesis: a balance between inheritance and reprogramming? Curr Opin Cell Biol. 2012;24:387-96.

Girard A, Hannon GJ. Conserved themes in small-RNA-mediated transposon control. Trends Cell Biol. 2008;18:136-48.

Girard A, Sachidanandam R, Hannon GJ, Carmell MA. A germline-specific class of small RNAs binds mammalian Piwi proteins. $\mathrm{Na}-$ ture. 2006;442:199-202.

Goh WS, Falciatori I, Tam OH, Burgess R, Meikar O, Kotaja N, et al. piRNA-directed cleavage of meiotic transcripts regulates spermatogenesis. Genes Dev. 2015;29: 1032-44.

Goodier JL. Restricting retrotransposons: a review. Mob DNA. 2016;7:16.

Gou LT, Dai P, Yang JH, Xue Y, Hu YP, Zhou Y, et al. Pachytene piRNAs instruct massive mRNA elimination during late spermiogenesis. Cell Res. 2014;24:680-700.

Grivna ST, Beyret E, Wang Z, Lin H. A novel class of small RNAs in mouse spermatogenic cells. Genes Dev. 2006;20:1709-14.

Haase AD, Macfarlan TS. PiRNAs Rise to Rescue Koalas. Cell. 2019;179:582-3.

Hackett JA, Sengupta R, Zylicz JJ, Murakami K, Lee C, Down TA, et al. Germline DNA demethylation dynamics and imprint erasure through 5-hydroxymethylcytosine. Science. 2013;339:448-52.

Hajkova P. Epigenetic reprogramming in the germline: towards the ground state of the epigenome. Philos Trans R Soc Lond B Biol Sci. 2011;366:2266-73.

Han BW, Wang W, Li C, Weng Z, Zamore PD, Noncoding RNA. Noncoding RNA. piRNAguided transposon cleavage initiates Zucchini-dependent, phased piRNA production. Science. 2015;348:817-21.

Hancks DC, Kazazian HH Jr. Active human retrotransposons: variation and disease. Curr Opin Genet Dev. 2012;22:191-203.

Handel MA, Schimenti JC. Genetics of mammalian meiosis: regulation, dynamics and impact on fertility. Nat Rev Genet. 2010;11:12436. 
Hargan-Calvopina J, Taylor S, Cook H, Hu Z, Lee SA, Yen MR, et al. Stage-Specific Demethylation in Primordial Germ Cells Safeguards against Precocious Differentiation. Dev Cell. 2016;39:75-86.

Hasegawa K, Sin HS, Maezawa S, Broering TJ, Kartashov AV, Alavattam KG, et al. SCML2 Establishes the Male Germline Epigenome through Regulation of Histone H2A Ubiquitination. Dev Cell. 2015;32:574-88.

Hata K, Okano M, Lei H, Li E. Dnmt3L cooperates with the Dnmt3 family of de novo DNA methyltransferases to establish maternal imprints in mice. Development. 2002;129:198393.

Hayashi K, de Sousa Lopes SM, Surani MA. Germ cell specification in mice. Science. 2007;316: 394-6.

Hickman AB, Dyda F. DNA Transposition at Work. Chem Rev. 2016;116:12758-84.

Hill PWS, Leitch HG, Requena CE, Sun Z, Amouroux R, Roman-Trufero M, et al. Epigenetic reprogramming enables the transition from primordial germ cell to gonocyte. $\mathrm{Na}$ ture. 2018;555:392-6.

Hirota T, Blakeley P, Sangrithi MN, Mahadevaiah SK, Encheva V, Snijders AP, et al. SETDB1 Links the Meiotic DNA Damage Response to Sex Chromosome Silencing in Mice. Dev Cell. 2018;47:645-e6.

Huang H, Gao Q, Peng X, Choi SY, Sarma K, Ren $\mathrm{H}$, et al. piRNA-associated germline nuage formation and spermatogenesis require MitoPLD profusogenic mitochondrial-surface lipid signaling. Dev Cell. 2011;20:376-87.

Hunter N. Meiotic Recombination: The Essence of Heredity. Cold Spring Harb Perspect Biol. $2015 ; 7$.

Imbeault M, Helleboid PY, Trono D. KRAB zincfinger proteins contribute to the evolution of gene regulatory networks. Nature. 2017;543: $550-4$.

Inoue $\mathrm{K}$, Ichiyanagi $\mathrm{K}$, Fukuda $\mathrm{K}$, Glinka $\mathrm{M}$, Sasaki $\mathrm{H}$. Switching of dominant retrotransposon silencing strategies from posttranscriptional to transcriptional mechanisms during male germ-cell development in mice. PLoS Genet. 2017;13:e1006926.

Iwasaki YW, Siomi MC, Siomi H. PIWI-Interacting RNA: Its Biogenesis and Functions. Annu Rev Biochem. 2015;84:405-33.

Izumi N, Shoji K, Sakaguchi Y, Honda S, Kirino $\mathrm{Y}$, Suzuki T, et al. Identification and Functional Analysis of the Pre-piRNA 3' Trimmer in Silkworms. Cell. 2016;164:962-73.

Jachowicz JW, Bing X, Pontabry J, Bošković A, Rando OJ, Torres-Padilla ME. LINE-1 activation after fertilization regulates global chromatin accessibility in the early mouse embryo. Nat Genet. 2017;49:1502-10.

Jain D, Meydan C, Lange J, Claeys Bouuaert C, Lailler N, Mason CE, et al. rahu is a mutant allele of Dnmt3c, encoding a DNA methyltransferase homolog required for meiosis and transposon repression in the mouse male germline. PLoS Genet. 2017;13: e1006964
Jameson SA, Natarajan A, Cool J, DeFalco T, Maatouk DM, Mork L, et al. Temporal transcriptional profiling of somatic and germ cells reveals biased lineage priming of sexual fate in the fetal mouse gonad. PLoS Genet. 2012;8: e1002575.

Kafri T, Ariel M, Brandeis M, Shemer R, Urven L, McCarrey J, et al. Developmental pattern of gene-specific DNA methylation in the mouse embryo and germ line. Genes Dev. 1992;6: 705-14.

Kagiwada S, Kurimoto K, Hirota T, Yamaji M, Saitou M. Replication-coupled passive DNA demethylation for the erasure of genome imprints in mice. EMBO J. 2013;32:340-53.

Kaneda M, Okano M, Hata K, Sado T, Tsujimoto $\mathrm{N}$, Li E, et al. Essential role for de novo DNA methyltransferase Dnmt3a in paternal and maternal imprinting. Nature. 2004;429:9003 .

Kano H, Godoy I, Courtney C, Vetter MR, Gerton GL, Ostertag EM, et al. L1 retrotransposition occurs mainly in embryogenesis and creates somatic mosaicism. Genes Dev. 2009;23: 1303-12.

Kato Y, Kaneda M, Hata K, Kumaki K, Hisano M, Kohara Y, et al. Role of the Dnmt3 family in de novo methylation of imprinted and repetitive sequences during male germ cell development in the mouse. Hum Mol Genet. 2007;16: 2272-80.

Kazachenka A, Bertozzi TM, Sjoberg-Herrera MK, Walker N, Gardner J, Gunning R, et al. Identification, Characterization, and Heritability of Murine Metastable Epialleles: Implications for Non-genetic Inheritance. Cell. 2018; 175:1717e1213-71.

Kelleher ES. Retrotransposons: Stowaways in the Primordial Germline. Curr Biol. 2017;27: R1066-8.

Khazina E, Weichenrieder O. Non-LTR retrotransposons encode noncanonical RRM domains in their first open reading frame. Proc Natl Acad Sci U S A. 2009;106:731-6.

Kim S, Günesdogan U, Zylicz JJ, Hackett JA, Cougot $\mathrm{D}$, Bao S, et al. PRMT5 protects genomic integrity during global DNA demethylation in primordial germ cells and preimplantation embryos. Mol Cell. 2014;56:564-79.

Kluin PM, de Rooij DG. A comparison between the morphology and cell kinetics of gonocytes and adult type undifferentiated spermatogonia in the mouse. Int J Androl. 1981;4:475-93.

Kobayashi H, Sakurai T, Miura F, Imai M, Mochiduki K, Yanagisawa E, et al. High-resolution DNA methylome analysis of primordial germ cells identifies gender-specific reprogramming in mice. Genome Res. 2013;23: 616-27.

Kota SK, Feil R. Epigenetic transitions in germ cell development and meiosis. Dev Cell. 2010;19: 675-86.

Kramerov DA, Vassetzky NS SINEs, 2 Wiley Interdiscip Rev RNA; 2011.p. 772-86.

Kuff EL, Lueders KK. The intracisternal A-particle gene family: structure and functional aspects. Adv Cancer Res. 1988;51:183-276.
Kuramochi-Miyagawa S, Kimura T, Ijiri TW, Isobe T, Asada N, Fujita Y, et al. Mili, a mammalian member of piwi family gene, is essential for spermatogenesis. Development. 2004; 131:839-49.

Kuramochi-Miyagawa S, Watanabe T, Gotoh K, Totoki Y, Toyoda A, Ikawa M, et al. DNA methylation of retrotransposon genes is regulated by Piwi family members MILI and MIWI2 in murine fetal testes. Genes Dev. 2008;22:908-17.

Kuramochi-Miyagawa S, Watanabe T, Gotoh K, Takamatsu K, Chuma S, Kojima-Kita K, et al. $\mathrm{MVH}$ in piRNA processing and gene silencing of retrotransposons. Genes Dev. 2010;24: $887-92$.

La HM, Hobbs RM. Mechanisms regulating mammalian spermatogenesis and fertility recovery following germ cell depletion. Cell Mol Life Sci. 2019;76:4071-102.

Lander ES, Linton LM, Birren B, Nusbaum C, Zody MC, Baldwin J, et al. Initial sequencing and analysis of the human genome. Nature. 2001;409:860-921.

Lane N, Dean W, Erhardt S, Hajkova P, Surani A, Walter J, et al. Resistance of IAPs to methylation reprogramming may provide a mechanism for epigenetic inheritance in the mouse. Genesis. 2003;35:88-93.

Lau NC, Seto AG, Kim J, Kuramochi-Miyagawa S, Nakano T, Bartel DP, et al. Characterization of the piRNA complex from rat testes. Science. 2006;313:363-7.

Lees-Murdock DJ, De Felici M, Walsh CP. Methylation dynamics of repetitive DNA elements in the mouse germ cell lineage. Genomics. 2003;82:230-7.

Lesch BJ, Page DC. Genetics of germ cell development. Nat Rev Genet. 2012;13:781-94.

Levin HL, Moran JV. Dynamic interactions between transposable elements and their hosts. Nat Rev Genet. 2011;12:615-27.

Li E, Zhang Y. DNA methylation in mammals. Cold Spring Harb Perspect Biol. 2014;6: a019133.

Li JY, Lees-Murdock DJ, Xu GL, Walsh CP. Timing of establishment of paternal methylation imprints in the mouse. Genomics. 2004;84: 952-60.

Li XZ, Roy CK, Dong X, Bolcun-Filas E, Wang J, Han BW, et al. An ancient transcription factor initiates the burst of piRNA production during early meiosis in mouse testes. Mol Cell. 2013;50:67-81.

Lim SL, Qu ZP, Kortschak RD, Lawrence DM, Geoghegan J, Hempfling AL, et al. HENMT1 and piRNA Stability Are Required for Adult Male Germ Cell Transposon Repression and to Define the Spermatogenic Program in the Mouse. PLoS Genet. 2015;11: e1005620.

Liu S, Brind'Amour J, Karimi MM, Shirane K, Bogutz A, Lefebvre L, et al. Setdb1 is required for germline development and silencing of H3K9me3-marked endogenous retroviruses in primordial germ cells. Genes Dev. 2014;28: 2041-55. 
Ma L, Buchold GM, Greenbaum MP, Roy A, Burns $\mathrm{KH}$, Zhu $\mathrm{H}$, et al. GASZ is essential for male meiosis and suppression of retrotransposon expression in the male germline. PLoS Genet. 2009;5:e1000635.

Macfarlan TS, Gifford WD, Driscoll S, Lettieri K, Rowe HM, Bonanomi D, et al. Embryonic stem cell potency fluctuates with endogenous retrovirus activity. Nature. 2012;487:57-63.

Maezawa S, Sakashita A, Yukawa M, Chen X, Takahashi K, Alavattam KG, et al. Super-enhancer switching drives a burst in gene expression at the mitosis-to-meiosis transition. Nat Struct Mol Biol. 2020;27:978-88.

Manakov SA, Pezic D, Marinov GK, Pastor WA, Sachidanandam R, Aravin AA. MIWI2 and MILI Have Differential Effects on piRNA Biogenesis and DNA Methylation. Cell Rep. 2015; 12:1234-43.

Mandal PK, Kazazian HH Jr. SnapShot: Vertebrate transposons. Cell. 2008;135:192-e1.

Martin SL, Branciforte D. Synchronous expression of LINE-1 RNA and protein in mouse embryonal carcinoma cells. Mol Cell Biol. 1993; 13:5383-92.

Martin SL, Bushman FD. Nucleic acid chaperone activity of the ORF1 protein from the mouse LINE-1 retrotransposon. Mol Cell Biol. 2001; 21:467-75.

Mathias SL, Scott AF, Kazazian HH Jr., Boeke JD, Gabriel A. Reverse transcriptase encoded by a human transposable element. Science. 1991; 254:1808-10

McCarrey JR. Toward a more precise and informative nomenclature describing fetal and neonatal male germ cells in rodents. Biol Reprod. 2013;89:47.

McClintock B. The origin and behavior of mutable loci in maize. Proc Natl Acad Sci U S A. 1950;36:344-55.

Mietz JA, Grossman Z, Lueders KK, Kuff EL. Nucleotide sequence of a complete mouse intracisternal A-particle genome: relationship to known aspects of particle assembly and function. J Virol. 1987;61:3020-9.

Mohn F, Handler D, Brennecke J, Noncoding RNA. Noncoding RNA. piRNA-guided slicing specifies transcripts for Zucchini-dependent, phased piRNA biogenesis. Science. 2015;348:812-7.

Molaro A, Falciatori I, Hodges E, Aravin AA, Marran K, Rafii S, et al. Two waves of de novo methylation during mouse germ cell development. Genes Dev. 2014;28:1544-9.

Moran JV, Holmes SE, Naas TP, DeBerardinis RJ, Boeke JD, Kazazian HH Jr. High frequency retrotransposition in cultured mammalian cells. Cell. 1996;87:917-27.

Mouse Genome Sequencing C, Waterston RH, Lindblad-Toh K, Birney E, Rogers J, Abril JF, et al. Initial sequencing and comparative analysis of the mouse genome. Nature. 2002;420: $520-62$.

Myers JS, Vincent BJ, Udall H, Watkins WS, Morrish TA, Kilroy GE, et al. A comprehensive analysis of recently integrated human $\mathrm{Ta} \mathrm{L} 1$ elements. Am J Hum Genet. 2002;71:312-26.
Nagano R, Tabata S, Nakanishi Y, Ohsako S, Kurohmaru M, Hayashi Y. Reproliferation and relocation of mouse male germ cells (gonocytes) during prespermatogenesis. Anat Rec. 2000;258:210-20.

Newkirk SJ, Lee S, Grandi FC, Gaysinskaya V, Rosser JM, Vanden Berg N, et al. Intact piRNA pathway prevents L1 mobilization in male meiosis. Proc Natl Acad Sci U S A. 2017;114: E5635-44.

Nguyen DH, Soygur B, Peng SP, Malki S, Hu G, Laird DJ. Apoptosis in the fetal testis eliminates developmentally defective germ cell clones. Nat Cell Biol. 2020;22:1423-35.

Nie Y, Wilson AF, DeFalco T, Meetei AR, Namekawa SH, Pang Q. FANCD2 is required for the repression of germline transposable elements. Reproduction. 2020;159:659-68.

Nishimura T, Nagamori I, Nakatani T, Izumi N, Tomari Y, Kuramochi-Miyagawa S, et al. PNLDC1, mouse pre-piRNA Trimmer, is required for meiotic and post-meiotic male germ cell development. EMBO Rep. 2018;19.

Ooi SK, Qiu C, Bernstein E, Li K, Jia D, Yang Z, et al. DNMT3L connects unmethylated lysine 4 of histone $\mathrm{H} 3$ to de novo methylation of DNA. Nature. 2007;448:714-7.

Ozata DM, Gainetdinov I, Zoch A, O'Carroll D, Zamore PD. PIWI-interacting RNAs: small RNAs with big functions. Nat Rev Genet. 2019;20:89-108.

Ozata DM, Yu T, Mou H, Gainetdinov I, Colpan C, Cecchini K, et al. Evolutionarily conserved pachytene piRNA loci are highly divergent among modern humans. Nat Ecol Evol. 2020; 4:156-68.

Pace JK, 2nd, Feschotte C. The evolutionary history of human DNA transposons: evidence for intense activity in the primate lineage. Genome Res. 2007;17:422-32.

Pastor WA, Stroud H, Nee K, Liu W, Pezic D, Manakov S, et al. MORC1 represses transposable elements in the mouse male germline. Nat Commun. 2014;5:5795.

Percharde M, Lin CJ, Yin Y, Guan J, Peixoto GA, Bulut-Karslioglu A, et al. A LINE1-Nucleolin Partnership Regulates Early Development and ESC Identity. Cell. 2018;174:391-e19.

Raiz J, Damert A, Chira S, Held U, Klawitter S, Hamdorf $\mathrm{M}$, et al. The non-autonomous retrotransposon SVA is trans-mobilized by the human LINE-1 protein machinery. Nucleic Acids Res. 2012;40:1666-83.

Rangwala SH, Zhang L, Kazazian HH Jr. Many LINE1 elements contribute to the transcriptome of human somatic cells. Genome Biol. 2009; 10:R100.

Rathke C, Baarends WM, Awe S, Renkawitz-Pohl R. Chromatin dynamics during spermiogenesis. Biochim Biophys Acta. 2014;1839:155-68.

Rebollo R, Romanish MT, Mager DL. Transposable elements: an abundant and natural source of regulatory sequences for host genes. Annu Rev Genet. 2012;46:21-42.

Reik W, Dean W, Walter J. Epigenetic reprogramming in mammalian development. Science. 2001;293:1089-93.
Reuter M, Berninger P, Chuma S, Shah H, Hosokawa M, Funaya C, et al. Miwi catalysis is required for piRNA amplification-independent LINE1 transposon silencing. Nature. 2011; 480:264-7.

Richardson BE, Lehmann R. Mechanisms guiding primordial germ cell migration: strategies from different organisms. Nat Rev Mol Cell Biol. 2010;11:37-49.

Saito K, Sakaguchi Y, Suzuki T, Suzuki T, Siomi H, Siomi MC. Pimet, the Drosophila homolog of HEN1, mediates 2'-O-methylation of Piwiinteracting RNAs at their 3 ' ends. Genes Dev. 2007;21:1603-8.

Saitou M, Yamaji M. Primordial germ cells in mice. Cold Spring Harb Perspect Biol. 2012;4.

Sakashita A, Kawabata Y, Jincho Y, Tajima S, Kumamoto S, Kobayashi H, et al. Sex Specification and Heterogeneity of Primordial Germ Cells in Mice. PLoS One. 2015;10:e0144836e0144836.

Sakashita A, Maezawa S, Takahashi K, Alavattam KG, Yukawa M, Hu YC, et al. Endogenous retroviruses drive species-specific germline transcriptomes in mammals. Nat Struct Mol Biol. 2020;27:967-77.

Sasaki H, Matsui Y. Epigenetic events in mammalian germ-cell development: reprogramming and beyond. Nat Rev Genet. 2008;9: 129-40.

Saxe JP, Chen M, Zhao H, Lin H. Tdrkh is essential for spermatogenesis and participates in primary piRNA biogenesis in the germline. EMBO J. 2013;32:1869-85.

Schopp T, Zoch A, Berrens RV, Auchynnikava T, Kabayama Y, Vasiliauskaite L, et al. TEX15 is an essential executor of MIWI2-directed transposon DNA methylation and silencing. Nat Commun. 2020;11:3739.

Schumann GG, Gogvadze EV, Osanai-Futahashi M, Kuroki A, Münk C, Fujiwara $\mathrm{H}$, et al. Unique functions of repetitive transcriptomes. Int Rev Cell Mol Biol. 2010;285:11588.

Seisenberger S, Andrews S, Krueger F, Arand J, Walter J, Santos F, et al. The dynamics of genome-wide DNA methylation reprogramming in mouse primordial germ cells. Mol Cell. 2012;48:849-62.

Seki Y, Yamaji M, Yabuta Y, Sano M, Shigeta M, Matsui Y, et al. Cellular dynamics associated with the genome-wide epigenetic reprogramming in migrating primordial germ cells in mice. Development. 2007;134:2627-38.

Senft AD, Macfarlan TS. Transposable elements shape the evolution of mammalian development. Nat Rev Genet. 2021;22:691-711. https: //doi.org/10.1038/s41576-021-003851.

Senti KA, Brennecke J. The piRNA pathway: a fly's perspective on the guardian of the genome. Trends Genet. 2010;26:499-509.

Shiromoto Y, Kuramochi-Miyagawa S, Daiba A, Chuma S, Katanaya A, Katsumata A, et al. GPAT2, a mitochondrial outer membrane protein, in piRNA biogenesis in germline stem cells. Rna. 2013;19:803-10. 
Shiromoto Y, Kuramochi-Miyagawa S, Nagamori I, Chuma S, Arakawa T, Nishimura T, et al. GPAT2 is required for piRNA biogenesis, transposon silencing, and maintenance of spermatogonia in micet. Biol Reprod. 2019; 101:248-56.

Shoji M, Tanaka T, Hosokawa M, Reuter M, Stark A, Kato Y, et al. The TDRD9-MIWI2 complex is essential for piRNA-mediated retrotransposon silencing in the mouse male germline. Dev Cell. 2009;17:775-87.

Smallwood SA, Kelsey G. De novo DNA methylation: a germ cell perspective. Trends Genet. 2012;28:33-42.

Sookdeo A, Hepp CM, McClure MA, Boissinot S. Revisiting the evolution of mouse LINE-1 in the genomic era. Mob DNA. 2013;4:3.

Soper SF, van der Heijden GW, Hardiman TC, Goodheart M, Martin SL, de Boer P, et al. Mouse maelstrom, a component of nuage, is essential for spermatogenesis and transposon repression in meiosis. Dev Cell. 2008;15:28597.

Soumillon M, Necsulea A, Weier M, Brawand D, Zhang $\mathrm{X}, \mathrm{Gu} \mathrm{H}$, et al. Cellular source and mechanisms of high transcriptome complexity in the mammalian testis. Cell Rep. 2013;3: 2179-90.

Spiller C, Koopman P, Bowles J. Sex Determination in the Mammalian Germline. Annu Rev Genet. 2017;51:265-85.

Tachibana M, Nozaki M, Takeda N, Shinkai Y. Functional dynamics of $\mathrm{H} 3 \mathrm{~K} 9$ methylation during meiotic prophase progression. EMBO J. 2007;26:3346-59.

Tam PP, Snow MH. Proliferation and migration of primordial germ cells during compensatory growth in mouse embryos. J Embryol Exp Morphol. 1981;64:133-47.

Tharp ME, Malki S, Bortvin A. Maximizing the ovarian reserve in mice by evading LINE-1 genotoxicity. Nat Commun. 2020;11:330.

Thompson PJ, Macfarlan TS, Lorincz MC. Long Terminal Repeats: From Parasitic Elements to Building Blocks of the Transcriptional Regulatory Repertoire. Mol Cell. 2016;62:766-76.

Trelogan SA, Martin SL. Tightly regulated, developmentally specific expression of the first open reading frame from LINE-1 during mouse embryogenesis. Proc Natl Acad Sci U S A. 1995;92:1520-4.

Unhavaithaya Y, Hao Y, Beyret E, Yin H, Kuramochi-Miyagawa S, Nakano T, et al. MILI, a PIWI-interacting RNA-binding protein, is required for germ line stem cell self-renewal and appears to positively regulate translation. J Biol Chem. 2009;284:650719.

van der Heijden GW, Bortvin A. Transient relaxation of transposon silencing at the onset of mammalian meiosis. Epigenetics. 2009;4:769.

Vasiliauskaitè L, Vitsios D, Berrens RV, Carrieri C, Reik W, Enright AJ, et al. A MILI-independent piRNA biogenesis pathway empowers partial germline reprogramming. Nat Struct Mol Biol. 2017;24:604-6.
Vasiliauskaite L, Berrens RV, Ivanova I, Carrieri C, Reik W, Enright AJ, et al. Defective germline reprogramming rewires the spermatogonial transcriptome. Nat Struct Mol Biol. 2018; 25:394-404.

Veland N, Lu Y, Hardikar S, Gaddis S, Zeng Y, Liu B, et al. DNMT3L facilitates DNA methylation partly by maintaining DNMT3A stability in mouse embryonic stem cells. Nucleic Acids Res. 2019;47:152-67.

Vincent JJ, Huang Y, Chen PY, Feng S, Calvopiña $\mathrm{JH}$, Nee K, et al. Stage-specific roles for tet 1 and tet2 in DNA demethylation in primordial germ cells. Cell Stem Cell. 2013;12:4708

Vourekas A, Zheng K, Fu Q, Maragkakis M, Alexiou P, Ma J, et al. The RNA helicase MOV10L1 binds piRNA precursors to initiate piRNA processing. Genes Dev. 2015;29: 617-29.

Wang J, Saxe JP, Tanaka T, Chuma S, Lin H. Mili interacts with tudor domain-containing protein 1 in regulating spermatogenesis. Curr Biol. 2009a; 19:640-4.

Wang Y, Juranek S, Li H, Sheng G, Wardle GS, Tuschl T, et al. Nucleation, propagation and cleavage of target RNAs in Ago silencing complexes. Nature. 2009b;461:754-61.

Wang Y, Zhu T, Li Q, Liu C, Han F, Chen M, et al. Prmt5 is required for germ cell survival during spermatogenesis in mice. Sci Rep. 2015;5:11031.

Wang X, Lv C, Guo Y, Yuan S. Mitochondria Associated Germinal Structures in Spermatogenesis: piRNA Pathway Regulation and Beyond. Cells. 2020;9:399.

Wasik KA, Tam OH, Knott SR, Falciatori I, Hammell M, Vagin VV, et al. RNF17 blocks promiscuous activity of PIWI proteins in mouse testes. Genes Dev. 2015;29:1403-15.

Watanabe T, Chuma S, Yamamoto Y, Kuramochi-Miyagawa S, Totoki Y, Toyoda A, et al. MITOPLD is a mitochondrial protein essential for nuage formation and piRNA biogenesis in the mouse germline. Dev Cell. 2011;20: 364-75.

Watanabe T, Cheng EC, Zhong M, Lin H. Retrotransposons and pseudogenes regulate mRNAs and lncRNAs via the piRNA pathway in the germline. Genome Res. 2015;25:36880.

Watanabe T, Cui X, Yuan Z, Qi H, Lin H. MIWI2 targets RNAs transcribed from piRNA-dependent regions to drive DNA methylation in mouse prospermatogonia. EMBO J. 2018;37: e95329.

Webster KE, O'Bryan MK, Fletcher S, Crewther PE, Aapola U, Craig J, et al. Meiotic and epigenetic defects in Dnmt3L-knockout mouse spermatogenesis. Proc Natl Acad Sci U S A. 2005; 102:4068-73.

Wenda JM, Homolka D, Yang Z, Spinelli P, Sachidanandam R, Pandey RR, et al. Distinct Roles of RNA Helicases MVH and TDRD9 in PIWI Slicing-Triggered Mammalian piRNA Biogenesis and Function. Dev Cell. 2017;41:623e9.
Western PS, Miles DC, van den Bergen JA, Burton $\mathrm{M}$, Sinclair AH. Dynamic regulation of mitotic arrest in fetal male germ cells. Stem Cells. 2008;26:339-47.

Wu PH, Fu Y, Cecchini K, Özata DM, Arif A, Yu $\mathrm{T}$, et al. The evolutionarily conserved piRNAproducing locus pi6 is required for male mouse fertility. Nat Genet. 2020;52:728-39.

Yabuta Y, Ohta H, Abe T, Kurimoto K, Chuma S, Saitou M. TDRD5 is required for retrotransposon silencing, chromatoid body assembly, and spermiogenesis in mice. J Cell Biol. 2011; 192:781-95.

Yamaguchi S, Hong K, Liu R, Shen L, Inoue A, Diep $\mathrm{D}$, et al. Tet 1 controls meiosis by regulating meiotic gene expression. Nature. 2012; 492:443-7.

Yamaguchi S, Shen L, Liu Y, Sendler D, Zhang Y. Role of Tet1 in erasure of genomic imprinting. Nature. 2013;504:460-4.

Yamanaka S, Nishihara H, Toh H, Eijy Nagai LA, Hashimoto K, Park SJ, et al. Broad Heterochromatic Domains Open in Gonocyte Development Prior to De Novo DNA Methylation. Dev Cell. 2019;51:21-e5.

Yang F, Wang PJ. Multiple LINEs of retrotransposon silencing mechanisms in the mammalian germline. Semin Cell Dev Biol. 2016;59: $118-25$.

Yang F, Lan Y, Pandey RR, Homolka D, Berger SL, Pillai RS, et al. TEX15 associates with MILI and silences transposable elements in male germ cells. Genes Dev. 2020;34:745-50.

Yang Z, Chen KM, Pandey RR, Homolka D, Reuter M, Janeiro BK, et al. PIWI Slicing and EXD1 Drive Biogenesis of Nuclear piRNAs from Cytosolic Targets of the Mouse piRNA Pathway. Mol Cell. 2016;61:138-52.

Yoshida S. Heterogeneous, dynamic, and stochastic nature of mammalian spermatogenic stem cells. Curr Top Dev Biol. 2019;135:245-85.

Yoshida S, Sukeno M, Nakagawa T, Ohbo K, Nagamatsu G, Suda T, et al. The first round of mouse spermatogenesis is a distinctive program that lacks the self-renewing spermatogonia stage. Development. 2006;133:1495505.

Yoshimura T, Toyoda S, Kuramochi-Miyagawa S, Miyazaki T, Miyazaki S, Tashiro F, et al. Gtsf1/Cue110, a gene encoding a protein with two copies of a CHHC Zn-finger motif, is involved in spermatogenesis and retrotransposon suppression in murine testes. Dev Biol. 2009;335:216-27.

Yoshimura T, Watanabe T, Kuramochi-Miyagawa S, Takemoto N, Shiromoto Y, Kudo A, et al. Mouse GTSF1 is an essential factor for secondary piRNA biogenesis. EMBO Rep. 2018; 19:e42054

Yu T, Koppetsch BS, Pagliarani S, Johnston S, Silverstein NJ, Luban J, et al. The piRNA Response to Retroviral Invasion of the Koala Genome. Cell. 2019;179:632-e12.

Zamudio N, Bourc'his D.Transposable elements in the mammalian germline: a comfortable niche or a deadly trap? Heredity. 2010;105: 92-104.https://doi.org/10.1038/hdy.2010.53 
Zamudio N, Barau J, Teissandier A, Walter M, Borsos M, Servant N, et al. DNA methylation restrains transposons from adopting a chromatin signature permissive for meiotic recombination. Genes Dev. 2015;29:1256-70.

Zhang Y, Maksakova IA, Gagnier L, van de Lagemaat LN, Mager DL. Genome-wide assessments reveal extremely high levels of polymorphism of two active families of mouse endogenous retroviral elements. PLoS Genet. 2008;4:e1000007.
Zheng K, Xiol J, Reuter M, Eckardt S, Leu NA, McLaughlin KJ, et al. Mouse MOV10L1 associates with Piwi proteins and is an essential component of the Piwi-interacting RNA (piRNA) pathway. Proc Natl Acad Sci U S A. 2010;107:11841-6.

Zhang P, Kang JY, Gou LT, Wang J, Xue Y, Skogerboe G, et al. MIWI and piRNA-mediated cleavage of messenger RNAs in mouse testes. Cell Res. 2015;25:193-207.

Zhang J, Wang Q, Wang M, Jiang M, Wang Y, Sun $Y$, et al. GASZ and mitofusin-mediated mitochondrial functions are crucial for spermatogenesis. EMBO Rep. 2016;17:220-34.
Zhang Y, Guo R, Cui Y, Zhu Z, Zhang Y, Wu H, et al. An essential role for PNLDC1 in piRNA 3 ' end trimming and male fertility in mice. Cell Res. 2017;27:1392-6.

Zhou S, Feng S, Qin W, Wang X, Tang Y, Yuan S. Epigenetic Regulation of Spermatogonial Stem Cell Homeostasis: From DNA Methylation to Histone Modification. Stem Cell Rev Rep. 2021;17:562-80.

Zoch A, Auchynnikava T, Berrens RV, Kabayama $\mathrm{Y}$, Schöpp T, Heep M, et al. SPOCD1 is an essential executor of piRNA-directed de novo DNA methylation. Nature. 2020;584:635-9. 